WORKING PAPER · NO. 2021-13

Profiling Insurrection: Characterizing Collective Action Using Mobile Device Data

David Van Dijcke and Austin L. Wright

FEBRUARY 2021

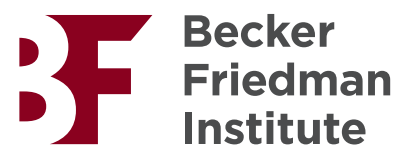




\title{
Profiling Insurrection Characterizing Collective Action Using Mobile Device Data ${ }^{1}$
}

\author{
David Van Dijcke ${ }^{1}$, Austin L Wright ${ }^{2}$ \\ 1 Department of Economics, University of Michigan \\ 2 Harris School of Public Policy, University of Chicago
}

February 10, 2021

\begin{abstract}
We develop a novel approach for estimating spatially dispersed community-level participation in mass protest. This methodology is used to investigate factors associated with participation in the 'March to Save America' event in Washington, D.C. on January 6, 2021. This study combines granular location data from more than 40 million mobile devices with novel measures of community-level voting patterns, the location of organized hate groups, and the entire georeferenced digital archive of the social media platform Parler. We find evidence that partisanship, socio-political isolation, proximity to chapters of the Proud Boys organization, and the local activity on Parler are robustly associated with protest participation. Our research fills a prominent gap in the study of collective action: identifying and studying communities involved in mass-scale events that escalate into violent insurrection.
\end{abstract}

Keywords: insurrections, protests, riots, collective action, big data, cellphone, mobile devices.

\footnotetext{
${ }^{1}$ We thank Bakdaulet Baitan for stellar research assistance. We also thank Ethan Bueno de Mesquita for helpful comments. Support from the Becker Friedman Institute for Research in Economics and the Belgian American Educational Foundation is gratefully acknowledged. All errors remain our own.
} 
Significance Statement This paper develops and implements a novel methodology for estimating community-level participation in mass protest events. This method represents an important contribution to our scientific understanding of where protests emerge and which communities participate. We evaluate this new method in the context of the recent episode of political violence in Washington, D.C. on January 6, 2021. We present the first robust evidence linking partisanship and political isolation to participation in the protest and subsequent riot at the U.S. Capitol. We also present results linking local use of Parler a social media platform used to spread election-related disinformation - as well as proximity to a regional Proud Boys headquarters to mobilization. This paper addresses a prominent gap in the study of collective action and political violence. 


\section{Introduction}

Understanding the origins and consequences of collective action is central to political economy. The processes that influence the emergence of collective opposition to political institutions are of vital interest to scholars and the public debate at large, not only when protests remain peaceful, but all the more so when they escalate into violence and when non-violent strategies devolve into riots and armed insurrection. How these events reshape political institutions, and under what conditions, remains a central feature of institutional change and political development. Unpacking the mechanisms that trigger collective action and explain downstream consequences requires a substantive exploration of those that participate in these social and political movements.

This paper highlights a prominent gap in our understanding of collective action - it is difficult to identify and study those engaged in protests - and proposes a method for addressing this gap. We apply this approach to a recent disruptive event in American politics, the protest and subsequent violent attempt to undermine democratic norms and institutions that occurred on January 6, 2021. We bring together a rich, novel set of microlevel characteristics to study the factors associated with variation in whether and how intensively community members engaged in this event. We provide evidence that socio-political isolation, proximity to a prominent hate group, the Proud Boys, as well as the intensity of local misinformation posts on social media are robustly associated with participation in this event. These insights also help clarify slanted coverage and misinformation about protest partici-

pants, which we detail in Table SI-10, including claims about the involvement of supporters of former President Trump, the Proud Boys, and the role of social media platforms, such as Parler.

Prior work has demonstrated the role of economic conditions, political repression, exclusion of racial, ethnic, or economic minorities, use of force, (mis)information campaigns 
and social media in explaining when and where protests (Steinert-Threlkeld, 2017; Chyzh and Labzina, 2018; Justino and Martorano, 2019; Fergusson and Molina, 2020; Martinez, Jessen and Xu, 2020; Enikolopov, Makarin and Petrova, 2020; Manacorda and Tesei, 2020), riots (Sullivan, 2019; Hsiao and Radnitz, 2020), violence (Müller and Schwarz, 2020), and armed opposition movements emerge (Oppenheim et al., 2015, Dippel and Heblich, 2021). A significant body of research has also provided evidence that these instances of collective action have affected political reforms (Tarrow, 1994, Rasler, 1996; Kurzman, 1996: Chenoweth and Stephan, 2008; Gillion, 2013; Andrews and Gaby, 2015; Klein and Regan, 2018; De Vogel, 2020), voting patterns (Wasow, 2020; Enos, Kaufman and Sands, 2019; Larreboure and González, 2019), social attitudes and cohesion (Branton et al., 2015; Muñoz and Anduiza, 2019; Mazumder, 2019), and economic activity.

While this vast body of work yields important insights about the conditions under which organized opposition emerges and what impact such opposition may have on the various institutions within which they are embedded, we know significantly less about the individuals that participate in these behaviors. This is due, in large part, to data limitations: it is difficult to characterize those engaged in collective action in a rigorous and representative manner. Ethnographic and survey-based approaches to this question raise concerns about representativeness, social desirability bias, and preference falsification (Simpson, Willer and Feinberg, 2018; Edwards and Arnon, 2019; Enikolopov, Makarin and Petrova, 2020; Mazumder, 2018; Cantoni et al., 2017; Bursztyn et al., 2019; Rosenfeld, 2017). Other work has studied the association between local political and economic conditions and where protests occur (Enos, Kaufman and Sands, 2019; Rozenas and Zhukov, 2019; Enikolopov et al., 2020; Manacorda and Tesei, 2020; Correa, 2020). This approach can yield meaningful evidence when the conditions that trigger protests and protest involvement are spatially proximate: those engaged in protest or other activities reside in the area where the event occurs. Yet mass protests often include participants from outside the immediate area where the event occurred. Col- 
lective action coordinated around focal landmarks, including regional or national seats of political power, is similarly difficult to investigate using this approach.

This paper makes two central contributions. First, we introduce an approach for estimating community-level participation in mass protest. This approach leverages historical information about cellphone device movement - anonymized and aggregated - to identify devices that visit sub-municipal regions where protests or other types of collective action have occurred. Based on that approach, we characterize communities where the devices originate even if the origin is not spatially proximate. This use of aggregated device movement data balances the precision of the corresponding geographic measures and potential concerns about individual privacy. Our geographic measures correspond to the lowest administrative unit for which the United States Census Bureau makes long form data, including the American Community Survey (ACS), available to the public. These measures therefore reflect the Bureau's commitment to disclosure avoidance, minimizing any potential revelation of sensitive, individual-specific information 1 This approach also resembles the use of aggregated movement data in a range of papers that investigate the link between community characteristics, social distancing, and viral spread during the COVID-19 pandemic Allcott et al., 2020; Brzezinski, Deiana, Kecht and Van Dijcke, 2020; Brzezinski, Kecht, Van Dijcke and Wright, 2020; Wright et al., 2020). Second, we apply this approach to the recent 'March to Save America' (MASA) event that involved a rally, protest, and subsequent violent riot on the grounds of the United States Capitol building (January 6, 2021). The aim of this event was to oppose or halt the official certification of the outcome of the November 2020 US presidential election. Characterizing those involved in the event helps clarify the conditions under which individuals may engage in such anti-democratic acts. We find that proximity to local chapters of a prominent hate group - the Proud Boys - as well as local engagement with online misinformation through the social-media platform Parler explain variation in

\footnotetext{
${ }^{1}$ For additional details, see https://bit.ly/3aewxfy.
} 
protest involvement, echoing some of the findings of the research cited above.

We begin by introducing our approach. This approach builds on our earlier work, which introduces a methodology for estimating when and where demonstrations or other massscale events occur using cellphone movement data. Specifically, device surges indicate areas where an anomalous congregation of devices has occurred. We validate this methodology by demonstrating that the primary zone in Washington, D.C. experiencing a device surge was the geographic area including the National Mall and U.S. Capitol grounds - where the protest and subsequent riot occurred. Importantly, nearly all of the anomalous activity in this zone can be attributed to devices originating outside of the greater municipal area where the event occurred. Next, we identify the geographic origin of each device and study how device activity on the day of the MASA event deviated from historical trends in visits to the same zone in Washington, D.C. Our approach yields several outcomes of interest for those interested in studying involvement in collective action.

Subsequently, we compile exceptionally granular data on community characteristics that matches the geographic information associated with the anonymized device data and compare the attributes of communities with varying levels of protest involvement. Given the spatial precision of our measurement approach, we can investigate a prominent hypothesis regarding protest involvement: the role of social isolation and intergroup threat perception. Theories of social isolation, dating at least to Durkheim's (1897) prominent work on anomie, suggest that perceived isolation can trigger feelings of fear and subsequent aggression (Merton, 1938; McDill and Ridley, 1962; Finifter, 1970). Given the context, we consider whether feelings of political isolation or exclusion might similarly influence protest involvement. Relatedly, a substantial body of work in sociology and psychology has explored the links between intergroup contact and collective action (Van Zomeren, Postmes and Spears, 2008; Van Zomeren, Leach and Spears, 2012). The focus of this literature has, however, been on collective action aimed at intergroup social progress, rather than at the advancement of 
in-group interests (Dovidio et al., 2017) $\left.\right|^{2}$ This research agenda has primarily focused on positive intergroup contact, leaving the potential consequences of negative contact or out-group proximity largely unexplored. Moreover, the consensus in the literature on intergroup contact is that such contact reduces prejudice and increases intergroup harmony (Pettigrew and Tropp, 2008; Allport, Clark and Pettigrew, 1954). Only recently has research turned towards the effects of negative intergroup contact, providing suggestive evidence that negative contact is in fact more influential than positive contact (Hayward et al., 2017; Graf, Paolini and Rubin, 2014). Studying the effect of intergroup contact on collective action among LGBT and heterosexual students (Reimer et al. 2017$)$ and white and non-white Americans (Hayward et al., 2018), negative intergroup contact has been found to mobilize disadvantaged groups but demobilize advantaged groups, while positive contact has the opposite effects. At the same time, in the context of the Kurdish-Turkish conflict, perceived threats from the proximity of an out-group, for example, have been found to be important predictors of collective action regardless of the social status of the group (Çakal et al. 2016). Such perceived threats have also been associated, in the context of the Northern Irish conflict, with more negative interpersonal contact (Tausch et al., 2007). Mitts (2019) also provides evidence that pro-ISIS online radicalization increases with local anti-Muslim animosity in Western Europe. We contribute to this literature by documenting the link between perceived isolation due to out-group proximity - whether Trump supporting communities are surrounded by communities that were more supportive of Trump's political rival - and participation in the MASA event in Washington, D.C.. Using novel data on micro-level voting patterns from the 2016 election, we find that participation in the MASA event increases with local support for former President Trump and this result is amplified when these communities are more politically isolated. Our use of country-wide election data matched to large-scale mobile

\footnotetext{
${ }^{2}$ As noted by Çakal et al. (2016, p.735), "current accounts of collective action have mostly focused on disadvantaged groups and this exclusive focus is partly dictated by the premise that individuals engage in collective action to redress a group-based inequality."
} 
device data, combined with our method for backing out community-level participation in collective action, provides unique behavioral evidence of the links between social isolation, intergroup contact and collective action, further buttressing earlier survey-based findings from the intergroup relations literature. Finally, our findings also relate to the social trust and ethnic diversity literature, which established robust links between residential segregation and social trust (Dinesen, Schaeffer and Sønderskov, 2020; Vallier, 2020).

The rest of this paper is organized as follows. Section 2 introduces existing and proposed measurement strategies. Section 3 describes our research design and describes our rich microdata on community characteristics. Section 4 introduces our main results as well as robustness checks. Section 5 concludes and outlines areas for future research.

\section{Measuring Protest Activity and Involvement}

In this section, we lay out our approach for profiling mass demonstration events using mobile device data, building on our earlier method for identifying the potential locations of such events (Van Dijcke and Wright, 2020). First, we review some recent approaches from the literature. Then, we briefly revisit our earlier method for measuring protest activity, before describing how we build on it to characterize protest involvement.

\section{Current Approaches}

Previous research has taken a number of approaches for measuring the location, timing, and involvement of individuals in protest activities (and related collective action, such as riots).

One of the more common approaches is to leverage traditional media (usually newspaper or journalistic accounts) to gather information about when protests have occurred and their estimated scale (Enikolopov, Makarin and Petrova, 2020; Steinert-Threlkeld et al., 2015; Wasow, 2020; Carter and Carter, 2016; Acemoglu, Hassan and Tahoun, 2018; Lacina, 
2014; Carey, 2006; Manacorda and Tesei, 2020; Christensen and Garfias, 2018). Processing this information can be labor-intensive, as in (Wasow, 2020), which uses human coders; or computationally dependent, using algorithms to estimate event location and other event characteristics (Steinert-Threlkeld et al., 2015; Acemoglu, Hassan and Tahoun, 2018; Manacorda and Tesei, 2020). Coverage of protest events may suffer from a range of measurement biases - though Sobolev et al. (2020) use cellphone data to validate traditional crowd estimates of the 2017 United States Women's March protests, with favorable results. Source diversity, including social media posts (Larson et al., 2019; Acemoglu, Hassan and Tahoun, 2018; Won, Steinert-Threlkeld and Joo, 2017; Zhang and Pan, 2019; Spangler and Smith, 2021), can also be used to address concerns about reporting biases in traditional media (Nam, 2006; Enikolopov, Makarin and Petrova, 2020; Wasow, 2020; Madestam et al., 2013).

These approaches are useful for identifying protest locations and estimating crowd size. It is more difficult, however, to use them to measure protest involvement. Mass protests or collective action coordinated around focal landmarks can mobilize individuals from spatially distinct origins. Ethnographic and survey-based approaches can be used to fill this gap (Simpson, Willer and Feinberg, 2018; Edwards and Arnon, 2019; Enikolopov, Makarin and Petrova, 2020; Mazumder, 2018). Cantoni et al. (2017) and Bursztyn et al. (2019), for example, use surveys to capture self-reported participation in protest activities. Rosenfeld (2017) employs a novel survey-based approach, relying on survey collection during an active protest. Yet ethnographic or survey-based approaches have limitations as well, including representativeness and social desirability bias (where subjects distort or misrepresent their identity, involvement in the protest, and their motivations for participating in an event) Kuran, 1995). Moreover, they are inherently hard to scale, as opposed to cellphone data, which can relatively easily be used to study various protests across time and space $3^{3}$

\footnotetext{
${ }^{3}$ In Van Dijcke and Wright (2020), for example, we locate the George Floyd protests across the entire United States, over a period of several days. This would require enormous resources when using survey-based approaches.
} 


\section{Estimating Sites using Device Surges}

We rely on the mobile phone data described above to identify likely protest locations by detecting anomalous device activity at the Census Block Group level ('device surges') following the approach in Van Dijcke and Wright (2020). For ease, we restate this approach in detail. We begin by defining a variable that captures the surge in device movement in CBG $i$ on day $t, S_{i t}$, as $\frac{\text { count }_{i t}}{\text { count }_{i}}$ where $\overline{\text { count }_{i}}=\frac{\Sigma_{t=t 0-K-1}^{t_{0}-1} S_{i t}}{K}$ is the average number of devices observed per day over the week preceding the day of the first protests $t_{0}$. Devices that have a home in a given $\mathrm{CBG}$ (i.e., CBG residents) are excluded from the total daily device count for that CBG. Protests sites are classified as those locations on a given date where $S_{i t}$ exceeds a threshold value $\lambda$ (a surge ratio exceeding 300). Van Dijcke and Wright (2020) validate this approach against George Floyd protest locations identified from traditional media coverage and geo-hashes associated with social media posts (Ipsos data collection) $4^{4}$ In principle, device surges capture the anomalous congregation of devices in a given location, which could be used to identify any type of unexpected mass assembly of individuals (e.g., riots, mass scale violence). To calibrate our measure of device surges, we estimate the number of visitors coming from a given origin CBG $i$ on day $t$ in week $s$ by multiplying the raw device count by the post-stratification weights, that is,

$$
\text { Number of visitors }{ }_{i t s}=\text { Raw device } \text { count }_{i t} \times \frac{\text { Census population }_{i}}{\text { Number of devices residing }_{i s}},
$$

where Number of devices residing ${ }_{i s}$ is a count of the unique number of devices whose home location was estimated to be in CBG $i$ in week $s$.

Our primary use of this method is two-fold. First, we know with geographic precision where the MASA event took place (the National Mall and U.S. Capitol Building grounds). This enables us to validate the 'device surge' approach. Second, we can evaluate the geo-

\footnotetext{
${ }^{4}$ See the data presented here.
} 
graphic overlap between this measure and even more granular data on social media activity (geotagged video uploads of protest and riot activity on January 6, 2021). Validating this approach gives us additional confidence that devices passing through this geographic area are likely to have been linked to event participants, for which we can identify an origin community (i.e., CBG of residence).

\section{Community Involvement using Device Movement}

Once the protest location has been established using the various approaches above, we observe devices that pass through and remain (for at least 1 minute) in the identified geographic zone on January 6. While we do not observe any individual device characteristics, we have information about the corresponding $\mathrm{CBG}$ of origin (i.e., the community where the device typically resides). This allows us to link protest devices to communities of origin even if the devices traveled significant distances to participate in the event. This is an important improvement over prior attempts to study mass protest events since participants may not originate near the protest site, particularly for a large-scale event coordinated around a focal landmark (e.g., the U.S. Capitol Building, Pushkin Square (Russia), Azadi Square (Iran), Tahrir Square (Egypt)).

Because we use anonymized and aggregated data, we cannot fully distinguish between devices passing through the identified protest CBG to participate in the MASA event and those arriving at this location for other purposes (e.g., members of Congress, security details, tourists). To address this, we rely on the historical network of origin-to-destination traffic to identify the trend in movement from origin CBGs through the protest site in the month prior to the event $5^{5}$ This approach allows us to partial out any baseline traffic between the

\footnotetext{
${ }^{5}$ We demonstrate that the results are similar using trends with a longer base period (two, three months). We prefer using traffic as temporally proximate to the event as possible since there may be other unrelated events that introduce noise to the trend when using a longer pre-event base period. Year-on-year detrending is another possibility, though the COVID-19 pandemic makes it unsuitable for the present study. It is also more fallible to changes in the urban landscape.
} 
origin-destination network, leaving us with a measure of anomalous device movement, which should capture movement of protesters (i.e., devices that would otherwise not pass through the protest area in the absence of the protest itself) ${ }^{6}$ Since there may still be some residual variation due to devices residing close to the protest area, we focus on the sample of devices linked to origin CBGs outside of Washington, D.C.7

To construct a representative and comprehensive profile of the event, we assemble a crosssectional dataset of all of the 219,334 CBGs in the US. For each of these CBGs, we use, as our baseline regression outcome variable, the logs of the demeaned number of visitors,

$$
\left.\log \left(1+\text { Number of visitors }_{i t}\right)\right|_{t=\mathrm{Jan}_{6}}-\log \left(1+\overline{\text { Number of visitors }}_{i}\right) .
$$

This gives us a measure of relative anomalous traffic through the protest location CBG on January 6$]^{8}$ Leveraging the national cross-section of origin communities enables us to explore the factors that influence either the extensive margin of participation (whether any community member was observed in the vicinity of the MASA event) as well as the intensive margin (how many community members likely participated in the event).

\section{Data and Research Design}

\section{Overview}

Once the network of origin-to-destination CBGs has been established, we can link granular data on demographic and socio-economic information with the geographic cross-section at a national scale. This includes characteristics of more than 200,000 communities. We

\footnotetext{
${ }^{6} \mathrm{~A}$ similar approach is taken in (Coston et al. 2020 p.5).

${ }^{7}$ Including devices originating from communities in D.C. does not materially affect the results, though some findings are less precise. We report these results in the Appendix.

${ }^{8}$ We present results for an alternative specification that leverages inverse hyperbolic differences as outcome. The results are highly consistent.
} 
supplement these features with novel data on the results of the 2016 Presidential election, which we have estimated using an original precinct-to-CBG algorithm.$^{9}$ This granular measure enables us to calculate both the origin CBG vote share as well as the voting patterns of neighboring communities, which we use to calculate relative support and identify what we label as islands - communities surrounded by neighborhoods with more support for the opposing candidate. We use this information to investigate the association between social and political isolation and protest involvement. We also leverage a feature of the Parler social media platform which allowed us to identify the geotagged coordinates of the universe of self-recorded videos posted. Video metadata was retrieved prior to the shutdown of the site, which was deemed by various private and public actors as a plausible platform for coordinated violent behavior against government actors. These videos were linked to both the events of January 6 - to validate the protest site measure - as well as the origin community where each video was uploaded. We also use information from the Southern Poverty Law Center to estimate proximity to local chapters of the Proud Boys, a far-right, neo-fascist hate group.

\section{Data}

Mobile Device Data. We rely on anonymous aggregated data from a panel of 40 million mobile devices, spread across the United States. Mobile device data has been obtained from SafeGraph, a data company that aggregates anonymized location data from numerous applications in order to provide insights about physical places, via the PlaceKey Community. The dataset is aggregated from raw GPS pings from an underlying, demographically representative sample of 40 million mobile devices. It was made available by SafeGraph to

\footnotetext{
${ }^{9}$ We use results from the 2016 election as opposed to the 2020 election due to data limitations; available precinct-level records are not as comprehensive. Data for 2016 results is available for most states, as detailed below. Data for 2020 results is available for fewer states and coverage varies within available states across precincts. Within-state variation makes it difficult, without additional geographic assumptions, to reliably measure isolation using CBG adjacency.
} 
academic researchers in the wake of the COVID-19 pandemic (Brzezinski, Kecht, Van Dijcke and Wright, 2020; Brzezinski, Deiana, Kecht and Van Dijcke, 2020) 10 We make use of SafeGraphs's Social Distancing Metrics, a data product originally created to study social distancing behavior during the pandemic, to study travel to protest locations in Washington DC on the dates of recent pro-Trump rallies.

Underlying the data is a panel of mobile devices with home locations in nearly all 200,000+ Census Block Groups (CBG) in the United States 11 A CBG contains on average 39 blocks and typically has a population of 600 to 3,000 residents. The home location of a device is determined as its common nighttime location over 6 weeks, at a Geohash-7 $(153 \mathrm{~m} \times 153 \mathrm{~m})$ precision. We cannot observe individual devices, but know the number of devices that have a home in a given CBG. The panel is rotated regularly and is demographically representative: correlation with salient characteristics such as race and income is around 0.97. ${ }^{12}$ The reason the sample attains this level of representativeness is that it is compiled from thousands of different sources, thus bias associated with any one single source is unlikely to drive inferences in the entire panel. To account for sampling bias at the CBG level, we adopt a post-stratification approach comparing the sample population in the SafeGraph data to that in the Census.

Parler Metadata. The metadata of nearly all videos posted on the alt-tech social media platform Parler was retrieved by a group of internet archivists (led by Twitter user donk_enby), by scraping the data from the website through Parler's API (donk_enby, 2020). This was possible because Parler did not have security measures in place that prevented automated scraping of its website's contents, effectively allowing the archivists to download all its publicly available content in a legal manner. At the time of writing, the data was

\footnotetext{
${ }^{10}$ See https://safegraph.com for information on how to obtain access.

${ }^{11} \mathrm{CBGs}$ with 5 devices or less are excluded for privacy reasons (disclosure avoidance).

${ }^{12}$ For a detailed discussion of SafeGraph's panel bias, see here.S
} 
in the process of being archived on the Internet Archive. All the data obtained was public information, free for anyone with a Parler user account to see. According to one of the archivists involved, "99.9"\% of content on Parler was obtained (Cameron, 2021).

We make use of the geolocation metadata associated with the $\sim 68,000$ geotagged videos online on the Parler website at the moment of the breach. Most self-recorded videos have so-called EXIF data attached to them, which usually includes GPS location data of where the video was recorded, unless it is removed ${ }^{13}$ We use this data to calculate the number of self-recorded videos posted on Parler since 2016, in each CBG. While the archive includes the metadata of all $\sim 1$ million videos hosted on Parler at the moment it was scraped, only $\sim 68,000$ had embedded geolocation data, most likely because the other videos were not self-recorded (f.e. reposted videos originally produced by large media companies).

Proud Boys Chapters. Data on the local chapters of the Proud Boys, a far-right, neofascist hate group, was obtained from the Southern Poverty Law Center, a non-profit tracking hate groups and extremist organizations in the United States. Their hate map lists all the known local chapters of the almost 1,600 extremist groups they track. We match this information to our other data on the basis of the lat-long centroid of the city in which the Proud Boys are active. Subsequently, we calculate, for each CBG, the distance to the nearest hate group as the shortest distance on the lat-long (WGS84) ellipsoid, in kilometers.

2016 Presidential Election Data. We intersect precinct-level result shapefiles from the 2016 Presidential Election, compiled by the Voting and Election Science Team at the University of Florida and Wichita State University (Voting and Election Science Team, 2018), with CBG shapefiles to obtain CBG-level election results. The latter are obtained as the weighted average of total votes for each candidate in each precinct that overlaps with a given CBG, where the weights are the share of each precinct's area that overlaps with the CBG's

\footnotetext{
${ }^{13}$ Several social media platforms automatically remove EXIF data, but Parler did not.
} 
area. We expect this method to produce accurate estimate of CBG-level vote tallies, since 95\% of Census Blocks were associated with a unique precinct in the 2008 election, and half of those that were not had no population (Amos, McDonald and Watkins, 2017). This match should be even better for Census Block Groups, which combine several Census Blocks. Due to the unavailability of precinct-level election results, we do not have CBG-level vote shares for the following states: Alabama, Connecticut, Indiana, Mississippi, New Jersey, New York, Ohio, Pennsylvania, West Virginia.

2016 American Community Survey. We obtain information on the demographic and socio-economic composition of CBGs from the 2016 American Community Survey $\sqrt[14]{\text { For the }}$ precise variables used, see Table SI-1.

\section{Design}

We study variation in participation in the MASA event at the community level. To investigate factors associated with protest involvement, we rely on cross-sectional variation in political, economic, and demographic characteristic. Our main specification focuses on variation across CBGs nationally, whereas secondary specifications include state and county fixed effects. These secondary specifications allow us to address potential concerns that some factors, including voting patterns and engagement on Parler, may be geographically correlated. Leveraging only the within-fixed effect variation partials out some of these potential sources of bias. For some covariates, particularly proximity to a local Proud Boys chapter, the high dimensional fixed effects approach (i.e., county-level intercepts) is likely to partial out most of the variation, reducing precision.

We begin our analysis by validating our method for estimating the potential location of the protest site. This approach, which we discuss above and in more detail below, confirms

\footnotetext{
${ }^{14}$ Obtained via the SafeGraph Open Census portal.
} 
the relevant CBG that serves as the destination site where the MASA event was concentrated.

To study which community-level factors are associated with participation in the MASA event, we estimate the following Ordinary Least Squares regression:

$$
\begin{array}{r}
\text { Protest }_{i}^{\text {type }}=\beta_{0}+\beta_{1} \cdot \text { Trump_Share }+\beta_{2} \cdot \text { Island }+\beta_{3} \cdot \text { Trump_Share } \times \text { Island }+ \\
+\beta_{4} \cdot \text { Proud_Boys }+\beta_{5} \cdot \text { Parler_Videos }+\gamma \cdot X_{i}+F E_{j}+\epsilon_{c}
\end{array}
$$

Where Protest ${ }_{i}^{\text {type }}$ indicates various measures of protest involvement (type) by community (i.e., CBG) $i$. Trump_Share indicates community-specific vote share for Donald Trump in the 2016 election, Island is a binary variable that indicates the neighborhoods surrounding community $i$ were more likely to support the Democratic presidential candidate in 2016, and Trump_Share $\cdot$ Island captures the marginal effect of Trump support in community $i$ when the surrounding communities supported Trump's opponent more strongly. We interpret the interaction as the marginal effect of Trump support among communities that are politically isolated. To calculate the political preferences of the communities surrounding the origin $\mathrm{CBG}$, we rely on queen adjacency. Given the geographic scale and otherwise arbitrary shape of CBG boundaries, this enables us to identify contiguity along edges and points. For an illustration of this approach, see Figure SI-2. Proud_Boys indicates proximity to the closest Proud Boys chapter (log) and Parler_Videos indicates the number of georeferenced Parler videos uploaded in a given CBG $(\log ) . X_{i}$ indicates a number of CBG level demographic, social, and economic characteristics. $F E_{j}$ is the level of fixed effect (level-specific intercept) $j$ introduced in the regression, which is either none, state-level, or county-level. Standard errors are clustered by county $c$ within which CBG $i$ is located.

Theoretically, we expect that protest involvement is increasing in Trump support, likely to be triggered by political exclusion (marginal effect), and increases with Parler activity $\left(\beta_{1}, \beta_{3}, \beta_{5}\right.$ will be positive). We anticipate that proximity to a Proud Boys chapter will be 
positively associated with protest involvement, so $\beta_{4}$ will be negative (involvement decreases with distance) 15

\section{Results}

Estimating the Protest Site We begin by validating the protest site estimation approach described in Van Dijcke and Wright (2020). The visual output of this estimation routine is presented in Figure1. Note that the red shaded polygon indicates the CBGs that exceed the $\lambda$ threshold (device surge $\geq 300$ ). The identified CBGs primarily include the National Mall and areas near the U.S. Capitol Building grounds. These are the areas of Washington, D.C. that journalistic coverage suggests were primarily impacted by the protest and subsequent riot. For a higher $\lambda(\geq 417)$ threshold, we can obtain only the Capitol CBG; we focus on that $\mathrm{CBG}$ for the rest of the analysis ${ }^{16}$ As a secondary validation test, we overlay all of the georeferenced Parler video content uploaded in the greater Washington, D.C. area on January 6, 2021. These geotags are indicated with cyan-colored dots. Notice that the geotagged uploads are clustered inside of the CBG classified using Van Dijcke and Wright (2020) methodology as a protest site and pinpoint the location of where devices were clustered within the protest CBG: the Ellipse of President's Park, the Washington Monument, and the grounds of the U.S. Capitol. Given this evidence, we can confidently identify the destination CBG used to estimate the corresponding origin-to-protest site network.

Mapping Origins In Figure 2, we visualize why the proposed approach is important in cases of mass-scale protests coordinated around focal landmarks. Using the protest site noted above, we plot the origin-to-protest site network for the day of the MASA event as

\footnotetext{
${ }^{15}$ See Section 1 for a discussion of the literature that grounds these expectations.

${ }^{16}$ In the appendix, we vary the $\lambda$, lowering it to 250 . Using this threshold, we identify several CBGs that border the main protest site that also experienced an increase in device activity. These locations are noted in Figure SI-1. We evaluate the origins of devices in these adjacent sites and find no evidence of additional community involvement beyond that captured by movement within the primary Capitol CBG.
} 
well as the four prior weeks (on the same day of the week, Wednesday). Links between origin communities and the protest site are illustrated with turquoise lines. The prior weeks demonstrate that traffic through the National Mall and U.S. Capitol grounds is dispersed nationally. On the date of the MASA event, however, the difference is stark, with a proliferation of device origins that were not present in the historical trend. The origin communities are noted in orange. The larger shift, both in scale and composition, of origin communities highlights that large-scale protests can mobilize participants that are spatially distinct from the site of the event. We illustrate this composition shift in Figure 3. Comparing panel (a), the base period used to quantify typical device movement along the origin-to-protest site network, and panel (b), the day of the MASA event, illustrates a large shift to the right tail in origin-level surges. We also observe a clear double peak distribution, suggesting a meaningful shift in traffic patterns. A Gaussian mixture model estimated on the two subsets of data detects only a single underlying distribution for the subset in the month prior to the protest, but three for the day of the protest itself. These changes indicate a large shift in the distribution of anomalous device activity, consistent with a potential change in the characteristics of the origin communities represented in the network data. We investigate these characteristics next.

Regression-based Evidence We present the estimates from Equation 1 in Table 1. In this specification, the outcome of interest is the change in the number of devices that passed through the protest site on the day of the MASA event using the prior month as a base period. This difference is stated in log terms. Notice that protest involvement is increasing in Trump vote share and the marginal effect is positive and precise. The marginal effect of the interaction indicates that political isolation triggered additional protest involvement as Trump support in the origin community increases. This finding is consistent with the sociological and psychological literature emphasizing the role of threat perceptions and proximity 
to an out-group in shaping collective mobilization and, in cases of negative inter-group contact, aggression and violence. Similarly, local ethnic animosity has been linked with online radicalization (Mitts, 2019). We demonstrate that these insights are relevant in contexts of partisan polarization (Hsiao and Radnitz, 2020). In Figure 4, we demonstrate that the primary regressors of interest (vote share and the associated marginal effect of isolation) are robust to all the alternative stepwise combinations of included regressors, across each of the alternative fixed effects approaches. In Figure SI-3, we demonstrate that the distributions of Trump vote share across origin communities classified as politically isolated (i.e., islands) exhibit common support and are sufficiently dense to estimate robust marginal effects (Hainmueller, Mummolo and $\mathrm{Xu}, 2019$ ). We further evaluate which communities underlie the relationship between protest participation and political isolation by leveraging a tertiary measure of isolation. This measure captures the tercile of the overall distribution of differences between origin communities and their adjacent neighbors (where positive values indicate the origin community is more supportive of Trump than the surrounding communities). We present these results in Table SI-3, where the island measure is split into three equally sized subsets, each capturing a third of the distribution. Notice that the role of isolation is captured by the top tercile - those pro-Trump communities most politically isolated. Figure SI-3 panel (b), demonstrates that this supplemental approach also has sufficient common support to estimate the marginal effects associated with political isolation and partisanship. Prior survey-based research suggests that political isolation and negative intergroup contact or proximity can trigger mobilization; our study provides an important piece of behavioral evidence of this theoretical mechanism in a high stakes setting (involvement in an anti-democratic movement).

Prior work has emphasized the role of social media and (dis)information dynamics in driving involvement in collective action, especially protests (Christensen and Garfias, 2018; Fergusson and Molina, 2020; Enikolopov et al., 2020; Manacorda and Tesei, 2020). Indeed, 
we find that protest involvement is also increasing with Parler video uploads, suggesting a likely correlation between slanted social media engagement and MASA participation. Proximity to the nearest Proud Boys chapter is also robustly correlated with participation, with communities closer to Proud Boy activity demonstrating a higher level of involvement with the MASA event. These results are consistent with the role of social capital in shaping broader collective action (Madestam et al., 2013; Dippel and Heblich, 2021). The results are consistent across various fixed effects specifications, though the Proud Boys proximity, which does not vary much within county, is imprecise in the most demanding specification. ${ }^{17}$ Similar results are obtained when focusing on the extensive margin: whether or not any individuals from a given community participated in the event. These results are presented in Table SI-4,

Robustness We present a number of robustness checks in the Appendix. In Table SI5. we demonstrate the findings are consistent when using an alternative inverse hyperbolic difference measure of protest involvement. The results are also consistent if we use a two month base period (Table SI-6) or three month base period (Table SI-7) to evaluate trends in origin-to-protest site movement prior to the MASA event. The main results are also robust if we include origin CBGs located within the municipal limits of Washington, D.C. (Table SI-8). Since we leverage spatial variation in voting patterns to study the role of Trump support and political isolation, it is important to take into consideration spatial dependence in our hypothesis testing. The main analysis does this by clustering standard errors by administrative county. In Table SI-9, we introduce results from an alternative approach that accounts for arbitrary spatial dependence (Colella et al. 2019). The main results remain consistently precise.

\footnotetext{
${ }^{17}$ Local use of Parler and the emergence of regional Proud Boys chapters can be conceptualized as posttreatment dynamics with respect to Trump support and political isolation. Figure 4 demonstrates that inclusion of these regressors does not meaningfully shift the primary model estimates.
} 


\section{Conclusion}

This paper introduces a method for estimating community-level involvement in protest events even if the event is not spatially proximate to the individuals participating. We present granular evidence validating a technique for estimating protest sites, which we then use to calibrate measures of origin-to-protest site traffic during a recent large-scale event that escalated into a violent riot: the 'March to Save America' on January 6, 2021. We provide evidence that participation is positively correlated with local Trump support and is further enhanced when these supporters are more politically isolated. We also find evidence of a robust link between proximity to a prominent hate group, Proud Boys, and protest participation as well as use of Parler, a social media site that was shut down in the wake of the MASA event over concerns it was being used to coordinate violent attacks against government actors. 


\section{References}

Acemoglu, Daron, Tarek A Hassan and Ahmed Tahoun. 2018. "Power of the Street: Evidence from Egypt's Arab Spring." The Review of Financial Studies 31(1):1-42.

Allcott, Hunt, Levi Boxell, Jacob Conway, Matthew Gentzkow, Michael Thaler and David Y Yang. 2020. "Polarization and public health: Partisan differences in social distancing during the Coronavirus pandemic." NBER Working Paper 26946.

Allport, Gordon Willard, Kenneth Clark and Thomas Pettigrew. 1954. The nature of prejudice. Addison-wesley Reading, MA.

Amos, Brian, Michael P McDonald and Russell Watkins. 2017. "When boundaries collide: Constructing a national database of demographic and voting statistics." Public Opinion Quarterly 81(S1):385-400.

Andrews, Kenneth T. and Sarah Gaby. 2015. "Local Protest and Federal Policy: The Impact of the Civil Rights Movement on the 1964 Civil Rights Act." Sociological Forum 30(S1):509-527.

Branton, Regina, Valerie Martinez-Ebers, Tony E. Carey Jr. and Tetsuya Matsubayashi. 2015. "Social Protest and Policy Attitudes: The Case of the 2006 Immigrant Rallies." American Journal of Political Science 59(2):390-402.

Brzezinski, Adam, Guido Deiana, Valentin Kecht and David Van Dijcke. 2020. "The covid-19 pandemic: government vs. community action across the united states." Covid Economics: Vetted and Real-Time Papers 7:115-156.

Brzezinski, Adam, Valentin Kecht, David Van Dijcke and Austin L Wright. 2020. "Belief in science influences physical distancing in response to covid-19 lockdown policies." University of Chicago, Becker Friedman Institute for Economics Working Paper (2020-56).

Bursztyn, Leonardo, Davide Cantoni, David Yang, Noam Yuchtman and Jane Zhang. 2019. Persistent political engagement: Social interactions and the dynamics of protest movements. Technical report Working Paper.

Çakal, Huseyin, Miles Hewstone, Meltem Güler and Anthony Heath. 2016. "Predicting support for collective action in the conflict between Turks and Kurds: Perceived threats as a mediator of intergroup contact and social identity." Group Processes \& Intergroup Relations 19(6):732-752.

Cameron, Dell. 2021. "Every Deleted Parler Post, Many With Users' Location Data, Has Been Archived.".

URL: $\quad$ https://gizmodo.com/every-deleted-parler-post-many-with-users-location-dat1846032466 
Cantoni, Davide, David Y Yang, Noam Yuchtman and Y Jane Zhang. 2017. Are protests games of strategic complements or substitutes? Experimental evidence from Hong Kong's democracy movement. Technical report National Bureau of Economic Research.

Carey, Sabine C. 2006. "The dynamic relationship between protest and repression." Political Research Quarterly 59(1):1-11.

Carter, Brett L and Erin Baggott Carter. 2016. Propaganda and Protest: Evidence from Post-Cold War Africa. Technical report Working paper, USC.

Chenoweth, Erica and Maria J. Stephan. 2008. "Why Civil Resistance Works: The Strategic Logic of Nonviolent Conflict." International Security 33(1):7-44.

Christensen, Darin and Francisco Garfias. 2018. "Can You Hear Me Now? How Communication Technology Affects Protest and Repression." Quarterly journal of political science 13(1):89.

Chyzh, Olga V. and Elena Labzina. 2018. "Bankrolling Repression? Modeling Third-Party Influence on Protests and Repression." American Journal of Political Science 62(2):312324.

Colella, Fabrizio, Rafael Lalive, Seyhun Orcan Sakalli and Mathias Thoenig. 2019. "Inference with Arbitrary Clustering." IZA Discussion Paper No. 12584.

Correa, Sofia. 2020. Persistent Protests. Technical report. Working Paper.

Coston, Amanda, Neel Guha, Derek Ouyang, Lisa Lu, Alexandra Chouldechova and Daniel E Ho. 2020. "Leveraging Administrative Data for Bias Audits: Assessing Disparate Coverage with Mobility Data for COVID-19 Policy." arXiv preprint arXiv:2011.07194 .

De Vogel, Sasha. 2020. Concessions and Differential Demobilization in Autocracy. Technical report. Working Paper.

Dinesen, Peter Thisted, Merlin Schaeffer and Kim Mannemar Sønderskov. 2020. "Ethnic diversity and social trust: A narrative and meta-analytical review." Annual Review of Political Science 23:441-465.

Dippel, Christian and Stephan Heblich. 2021. "Leadership in Social Movements: Evidence from the "Forty-Eighters" in the Civil War." American Economic Review 111(2):472-505. URL: https://www.aeaweb.org/articles?id=10.1257/aer.20191137

donk_enby. 2020. "Parler Tricks." Zenodo Repository .

Dovidio, John F, Angelika Love, Fabian MH Schellhaas and Miles Hewstone. 2017. "Reducing intergroup bias through intergroup contact: Twenty years of progress and future directions." Group Processes E Intergroup Relations 20(5):606-620. 
Durkheim, E. 1897. Suicide: A Study in Sociology. Routledge Taylor \& Francis.

Edwards, Pearce and Daniel Arnon. 2019. "Violence on Many Sides: Framing Effects on Protest and Support for Repression." British Journal of Political Science pp. 1-19.

Enikolopov, Ruben, Alexey Makarin and Maria Petrova. 2020. "Social Media and Protest Participation: Evidence From Russia." Econometrica 88(4):1479-1514.

URL: https://onlinelibrary.wiley.com/doi/abs/10.3982/ECTA14281

Enikolopov, Ruben, Alexey Makarin, Maria Petrova and Leonid Polishchuk. 2020. "Social Image, Networks, and Protest Participation." Networks, and Protest Participation (April 26, 2020).

Enos, Ryan D., Aaron R. Kaufman and Melissa L. Sands. 2019. "Can Violent Protest Change Local Policy Support? Evidence from the Aftermath of the 1992 Los Angeles Riot." American Political Science Review 113(4):1012-1028.

Fergusson, Leopoldo and Carlos Molina. 2020. Facebook Causes Protests. Technical report. Working Paper.

Finifter, Ada W. 1970. "Dimensions of Political Alienation." The American Political Science Review 64(2):389-410.

Fraley, Chris and Adrian E Raftery. 2002. "Model-Based Clustering, Discriminant Analysis, and Density Estimation." Journal of the American statistical Association 97(458):611-631.

Gillion, Daniel Q. 2013. The Political Power of Protest: Minority Activism and Shifts in Public Policy. Cambridge Studies in Contentious Politics Cambridge University Press.

Graf, Sylvie, Stefania Paolini and Mark Rubin. 2014. "Negative intergroup contact is more influential, but positive intergroup contact is more common: Assessing contact prominence and contact prevalence in five Central European countries." European Journal of Social Psychology 44(6):536-547.

Hainmueller, Jens, Jonathan Mummolo and Yiqing Xu. 2019. "How Much Should We Trust Estimates from Multiplicative Interaction Models? Simple Tools to Improve Empirical Practice." Political Analysis 27(2):163-192.

Hayward, Lydia E, Linda R Tropp, Matthew J Hornsey and Fiona Kate Barlow. 2017. "Toward a Comprehensive Understanding of Intergroup Contact: Descriptions and Mediators of Positive and Negative Contact Among Majority and Minority Groups." Personality and Social Psychology Bulletin 43(3):347-364.

Hayward, Lydia E, Linda R Tropp, Matthew J Hornsey and Fiona Kate Barlow. 2018. "How negative contact and positive contact with Whites predict collective action among racial and ethnic minorities." British Journal of Social Psychology 57(1):1-20. 
Hsiao, Yuan and Scott Radnitz. 2020. "Allies or Agitators? How Partisan Identity Shapes Public Opinion about Violent or Nonviolent Protests." Political Communication pp. 1-19.

Justino, Patricia and Bruno Martorano. 2019. "Redistributive Preferences and Protests in Latin America." Journal of Conflict Resolution 63(9):2128-2154.

Klein, Graig R. and Patrick M. Regan. 2018. "Dynamics of Political Protests." International Organization 72(2):485-521.

Kuran, Timur. 1995. Private Truths, Public Lies. Harvard University Press. URL: http://www.jstor.org/stable/j.ctvt1sgqt

Kurzman, Charles. 1996. "Structural Opportunity and Perceived Opportunity in SocialMovement Theory: The Iranian Revolution of 1979." American Sociological Review 61(1):153-170.

Lacina, Bethany. 2014. "How Governments Shape the Risk of Civil Violence: India's Federal Reorganization, 1950--56." American Journal of Political Science 58(3):720-738.

Larreboure, Magdalena and Felipe González. 2019. The impact of the Women's March on the U.S. House Election. Technical report. Working Paper.

Larson, Jennifer M, Jonathan Nagler, Jonathan Ronen and Joshua A Tucker. 2019. "Social Networks and Protest Participation: Evidence from 130 Million Twitter Users." American Journal of Political Science 63(3):690-705.

Madestam, Andreas, Daniel Shoag, Stan Veuger and David Yanagizawa-Drott. 2013. "Do Political Protests Matter? Evidence from the Tea Party Movement." The Quarterly Journal of Economics 128(4):1633-1685.

Manacorda, Marco and Andrea Tesei. 2020. "Liberation Technology: Mobile Phones and Political Mobilization in Africa." Econometrica 88(2):533-567.

URL: https://onlinelibrary.wiley.com/doi/abs/10.3982/ECTA14392

Martinez, Luis, Jonas Jessen and Guo Xu. 2020. A Glimpse of Freedom: Allied Occupation and Political Resistance in East Germany. Technical report Empirical Studies of Conflict Project.

Mazumder, Soumyajit. 2018. "The Persistent Effect of U.S. Civil Rights Protests on Political Attitudes." American Journal of Political Science 62(4):922-935.

Mazumder, Soumyajit. 2019. Black Lives Matter for Whites' Racial Prejudice: Assessing the Role of Social Movements in Shaping Racial Attitudes in the United States. Technical report. Working Paper.

McDill, Edward L. and Jeanne Clare Ridley. 1962. "Status, Anomia, Political Alienation, and Political Participation." American Journal of Sociology 68(2):205-213. 
Merton, Robert K. 1938. "Social Structure and Anomie." American Sociological Review $3(5): 672-682$.

Mitts, Tamar. 2019. "From Isolation to Radicalization: Anti-Muslim Hostility and Support for ISIS in the West." American Political Science Review 113(1):173-194.

Muñoz, Jordi and Eva Anduiza. 2019. "If a fight starts, watch the crowd': The effect of violence on popular support for social movements." Journal of Peace Research 56(4):485498.

Müller, Karsten and Carlo Schwarz. 2020. "Fanning the Flames of Hate: Social Media and Hate Crime." Journal of the European Economic Association . jvaa045.

URL: https://doi.org/10.1093/jeea/jvaa045

Nam, Taehyun. 2006. "What You Use Matters: Coding Protest Data." PS: Political Science E Politics 39(2):281-287.

Oppenheim, Ben, Abbey Steele, Juan F. Vargas and Michael Weintraub. 2015. "True Believers, Deserters, and Traitors: Who Leaves Insurgent Groups and Why." Journal of Conflict Resolution 59(5):794-823.

URL: https://doi.org/10.1177/0022002715576750

Pettigrew, Thomas F and Linda R Tropp. 2008. "How Does Intergroup Contact Reduce Prejudice? Meta-Analytic Tests of Three Mediators." European journal of social psychology 38(6):922-934.

Rasler, Karen. 1996. "Concessions, Repression, and Political Protest in the Iranian Revolution." American Sociological Review 61(1):132-152.

Reimer, Nils Karl, Julia C Becker, Angelika Benz, Oliver Christ, Kristof Dhont, Ulrich Klocke, Sybille Neji, Magdalena Rychlowska, Katharina Schmid and Miles Hewstone. 2017. "Intergroup contact and social change: Implications of negative and positive contact for collective action in advantaged and disadvantaged groups." Personality and Social Psychology Bulletin 43(1):121-136.

Rosenfeld, Bryn. 2017. "Reevaluating the Middle-Class Protest Paradigm: A Case-Control Study of Democratic Protest Coalitions in Russia." American Political Science Review 111(4):637-652.

Rozenas, Arturas and Yuri M. Zhukov. 2019. "Mass Repression and Political Loyalty: Evidence from Stalin's 'Terror by Hunger'." American Political Science Review 113(2):569-583.

Scrucca, Luca, Michael Fop, T. Brendan Murphy and Adrian E. Raftery. 2016. "mclust 5: clustering, classification and density estimation using Gaussian finite mixture models." The $R$ Journal 8(1):289-317.

URL: https://doi.org/10.32614/RJ-2016-021 
Simpson, Brent, Robb Willer and Matthew Feinberg. 2018. "Does Violent Protest Backfire? Testing a Theory of Public Reactions to Activist Violence." Socius 4:2378023118803189.

Sobolev, Anton, Keith Chen, Jungseock Joo and Zachary C Steinert-Threlkeld. 2020. "News and Geolocated Social Media Accurately Measure Protest Size Variation." American Political Science Review 114(4):1343-1351.

Spangler, Ethan and Ben Smith. 2021. "Let Them Tweet Cake: Estimating Public Dissent Using Twitter." Defence and Peace Economics pp. 1-20.

Steinert-Threlkeld, Zachary. 2017. "Spontaneous Collective Action: Peripheral Mobilization During the Arab Spring." American Political Science Review 111:379-403.

Steinert-Threlkeld, Zachary C, Delia Mocanu, Alessandro Vespignani and James Fowler. 2015. "Online social networks and offline protest." EPJ Data Science 4(1):19.

Sullivan, Heather. 2019. "Sticks, Stones, and Broken Bones: Protest Violence and the State." Journal of Conflict Resolution 63(3):700-726.

Tarrow, Sidney. 1994. Power in Movement: Social Movements, Collective Action and Politics. Cambridge Studies in Comparative Politics Cambridge University Press.

Tausch, Nicole, Tania Tam, Miles Hewstone, Jared Kenworthy and Ed Cairns. 2007. "Individual-level and group-level mediators of contact effects in Northern Ireland: The moderating role of social identification." British journal of social psychology 46(3):541556.

Vallier, Kevin. 2020. Trust in a Polarized Age. Oxford University Press.

Van Dijcke, David and Austin L Wright. 2020. "Using Mobile Device Traces to Improve Near-Real Time Data Collection During the George Floyd Protests." Available at SSRN 3621731 .

Van Zomeren, Martijn, Colin Wayne Leach and Russell Spears. 2012. "Protesters as "Passionate Economists": A Dynamic Dual Pathway Model of Approach Coping With Collective Disadvantage." Personality and Social Psychology Review 16(2):180-199.

Van Zomeren, Martijn, Tom Postmes and Russell Spears. 2008. "Toward an integrative social identity model of collective action: a quantitative research synthesis of three sociopsychological perspectives." Psychological bulletin 134(4):504.

Voting and Election Science Team. 2018. "2016 Precinct-Level Election Results.".

URL: https://doi.org/10.7910/DVN/NH5S2I

Wasow, Omar. 2020. "Agenda Seeding: How 1960s Black Protests Moved Elites, Public Opinion and Voting." American Political Science Review 114(3):638-659. 
Won, Donghyeon, Zachary Steinert-Threlkeld and Jungseock Joo. 2017. Protest Activity Detection and Perceived Violence Estimation from Social Media Images. pp. 786-794.

Wright, Austin L., Konstantin Sonin, Jesse Driscoll and Jarnickae Wilson. 2020. "Poverty and economic dislocation reduce compliance with COVID-19 shelter-in-place protocols." Journal of Economic Behavior Organization 180:544-554.

Zhang, Han and Jennifer Pan. 2019. "CASM: A Deep-Learning Approach for Identifying Collective Action Events with Text and Image Data from Social Media." Sociological Methodology 49(1):1-57. 
Figure 1: Potential Protest Sites Based on Device Surges vs. Recording Locations of Videos Posted on Parler: Storming of the Capitol, Jan 6, 2021

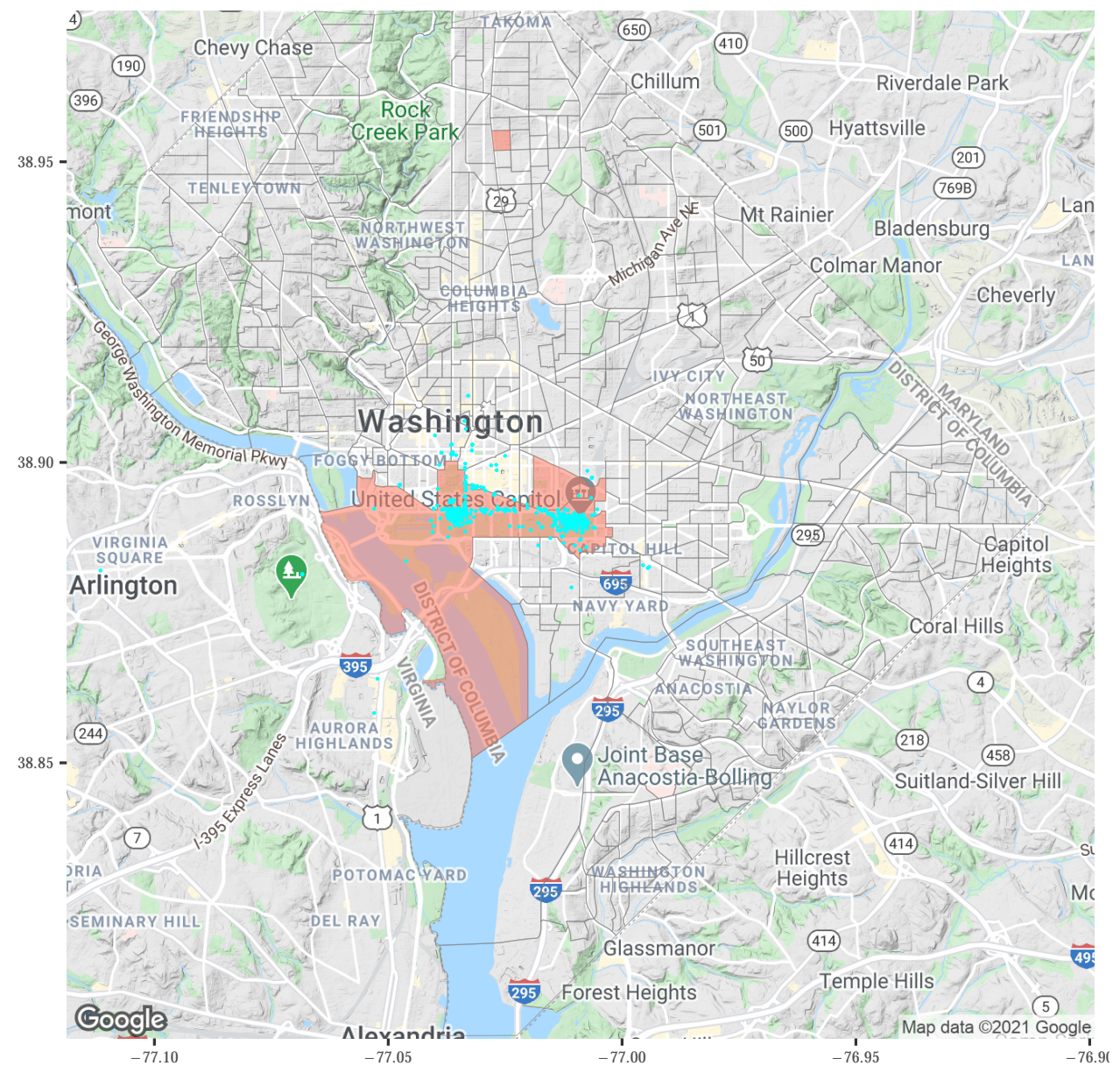

Notes:

1 Polygons with red fill indicate census block groups (CBGs) for which the ratio of the number of estimated visitors on Jan 6 to the average number of visitors to the same CBG in the week prior > 300. Gray lines indicate CBG polygon borders for all of DC.

${ }^{2}$ Cyan-colored dots indicate recording locations of videos uploaded to social-media website Parler on Jan 6. 
Figure 2: Travel Network to Protest CBGs, Day of Insurrection (Bottom) vs. Days Before

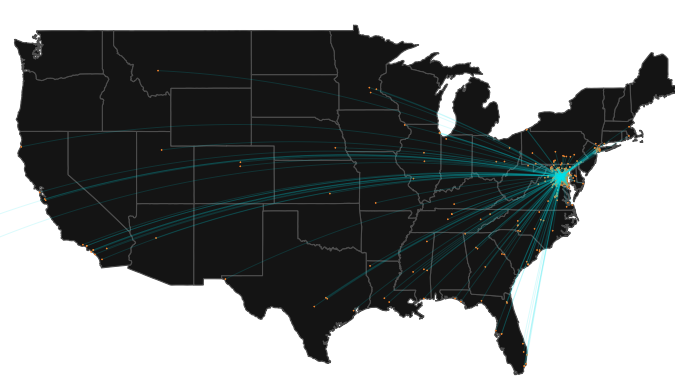

(a) Wed Dec 9, 2020

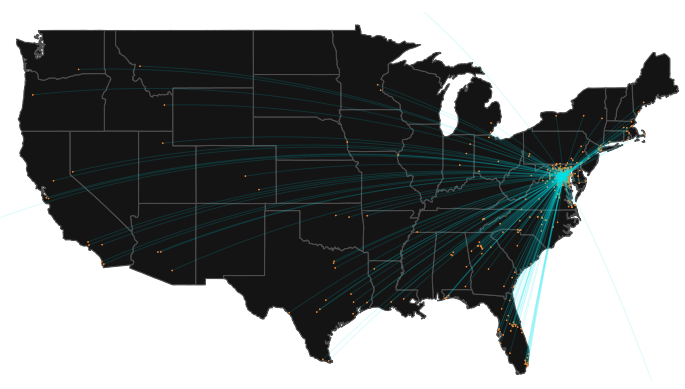

(c) Wed Dec 23, 2021

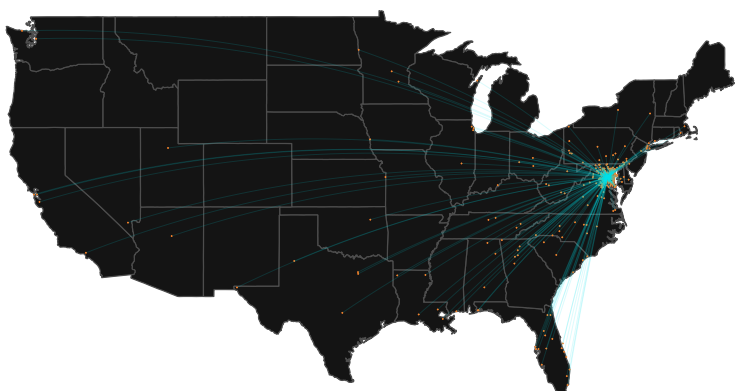

(b) Wed Dec 16, 2020

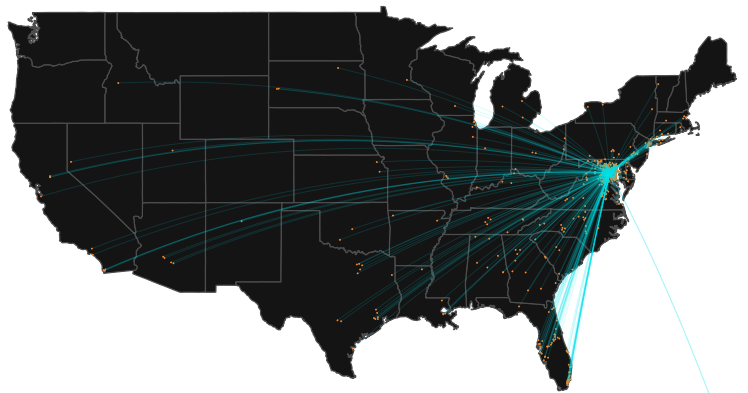

(d) Wed Dec 30, 2021

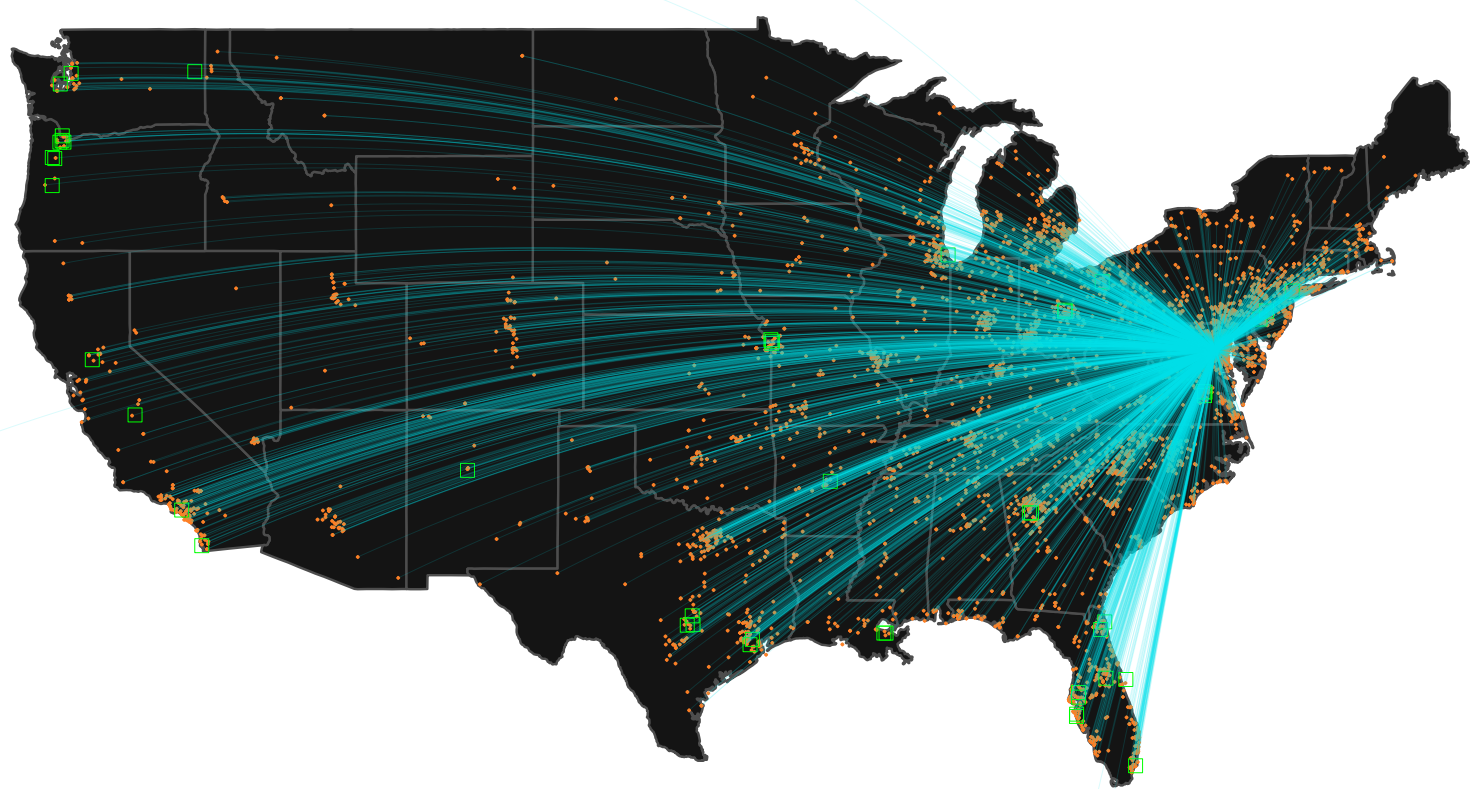

(e) Wed Jan 6, 2021: Storming of the Capitol

Notes:

${ }^{1}$ Figure shows origin and trajectories of mobile devices who visited the Capitol CBG, on the Wednesday of the storming of the Capitol (bottom) and the 4 Wednesdays preceding. Orange dots indicate the lat-long coordinates of the origin CBGs of the devices, turquoise lines show their shortest-distance trajectory. All figures are produced with identical visualization settings (transparency of lines, etc.).

${ }^{2}$ Green boxes in bottom figure mark the location of Proud Boys chapters, a prominent far-right hate group, according to the Southern Poverty Law Center. They correspond to the lat-long coordinates of the centroids of the city the chapter is in. 
Figure 3: Surge in Number of Visitors from Origin CBGs Going to Insurrection CBGs: One Month Before Insurrection vs. Jan 6

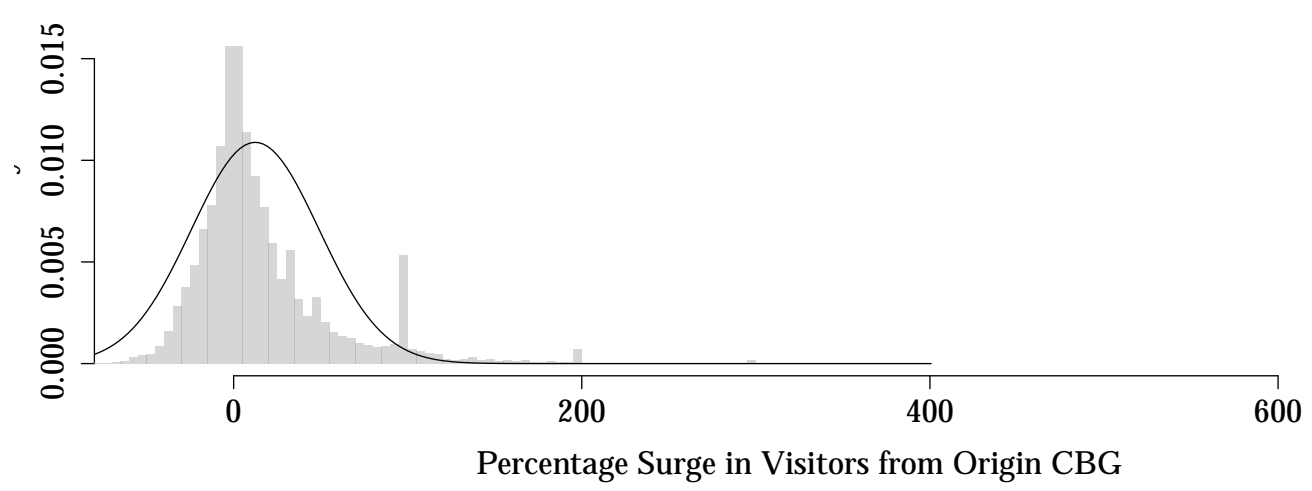

(a) December 1, 2020 to January 3, 2021, excl. protests

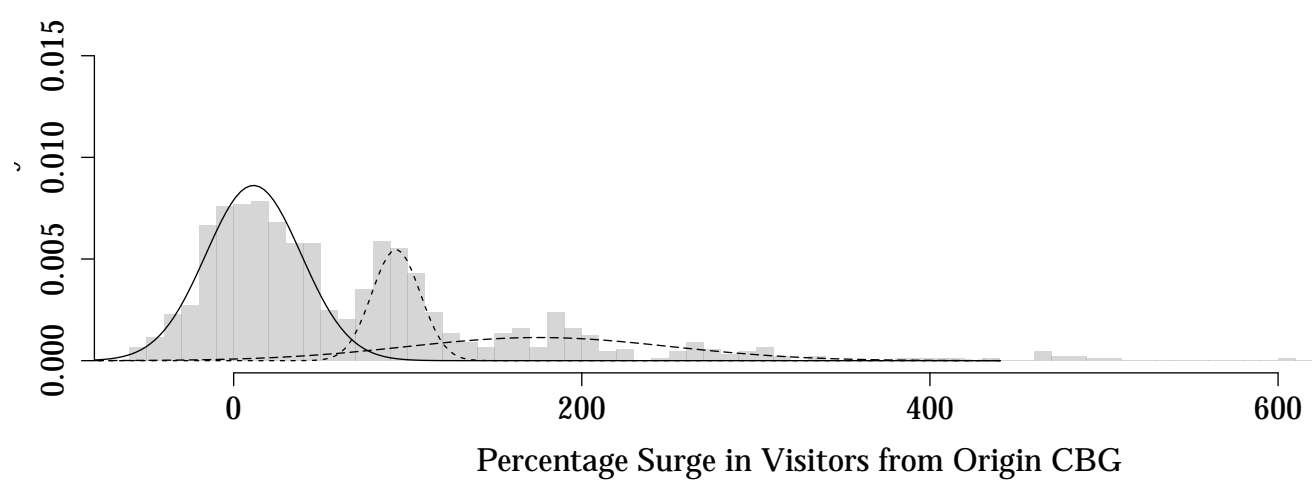

(b) January 6, 2021

${ }^{1}$ Grey bars depict histogram of percentage surge in number of visitors relative to average number of visitors in period from Dec 1, 2020 to Jan 3, 2021, conditional on there being any, from all origin CBGs that visited insurrection CBGs (i.e., CBGs where Jan 6 insurrection took place).

2 Density curves are estimated components of a univariate Gaussian mixture model with varying variance, estimated on all CBGs with surge $\leq 400$ (Fraley and Raftery, 2002; Scrucca et al., 2016).

3 Panel a) shows histogram for all dates between Dec 1, 2020 and Jan 3, 2021 combined, excluding other known large-scale protest dates (Dec 12). Panel b) shows histogram for day of insurrection. 
Figure 4: Coefficients of interest vs. t-statistics for all combinations of control regressors

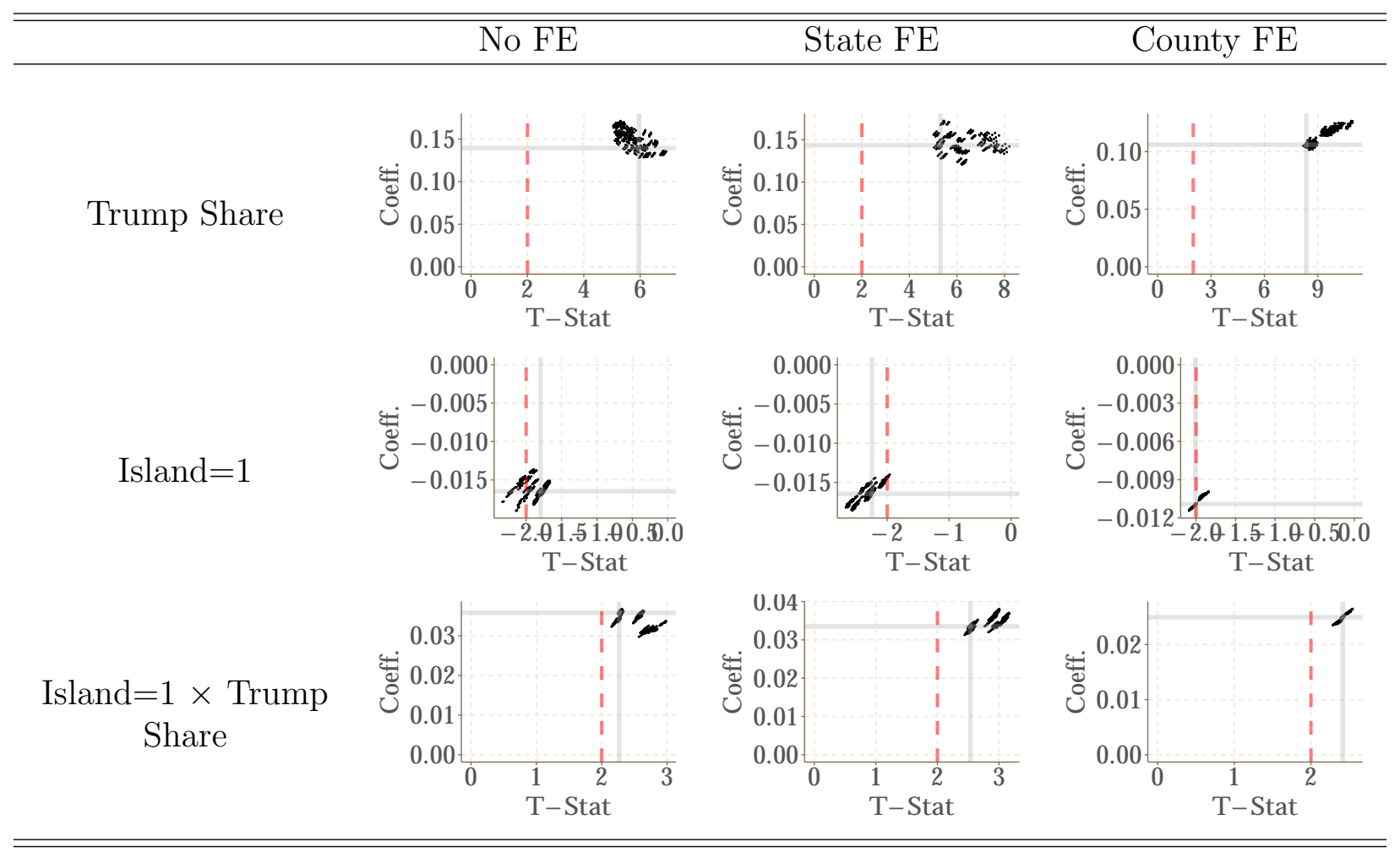

Notes:

1 Figures plot coefficient point estimates against t-statistics for all possible combinations of control variables of the baseline model, for any number of controls between 1 and the total number available. Grey shaded lines indicate baseline coefficients and t-stats, as reported in Table 1 .

2 Row names indicate variable for which coefficient estimates are plotted, column names indicate level at which intercepts vary.

3 Red dotted lines indicate t-stat corresponding to $95 \%$ significance level. All standard errors are clustered at the county level. 
Table 1: Factors associated with participation in the 'March to Save America' event, log differences

\begin{tabular}{|c|c|c|c|c|c|c|}
\hline \multirow[b]{2}{*}{ TRUMP } & \multicolumn{6}{|c|}{ Protesters $(\log \Delta), 1 m$} \\
\hline & & & & & & \\
\hline Trump Share & $0.139^{* * *}$ & $(0.0234)$ & $0.143^{* * *}$ & $(0.0270)$ & $0.106^{* * *}$ & $(0.0127)$ \\
\hline Island $=1$ & $-0.0164^{*}$ & $(0.00920)$ & $-0.0163^{* *}$ & $(0.00732)$ & $-0.0109^{* *}$ & $(0.00545)$ \\
\hline Island $=1 \times$ Trump Share & $0.0358^{* *}$ & $(0.0158)$ & $0.0335^{* *}$ & $(0.0132)$ & $0.0251^{* *}$ & $(0.0103)$ \\
\hline \multicolumn{7}{|l|}{ Census Block Group } \\
\hline Dist. to Proud Boys (Log) & $-0.00675^{* *}$ & $(0.00267)$ & $-0.0105^{* * *}$ & $(0.00325)$ & 0.0000707 & $(0.00274)$ \\
\hline \# Parler Videos (Log) & $0.0144^{* * *}$ & $(0.00389)$ & $0.0122^{* * *}$ & $(0.00372)$ & $0.00909^{* *}$ & $(0.00365)$ \\
\hline Median HH Income (Log) & -0.0171 & $(0.0150)$ & -0.00219 & $(0.00848)$ & $0.0186^{* * *}$ & $(0.00301)$ \\
\hline \multicolumn{7}{|l|}{ SHARE OF CBG POP: } \\
\hline Male & -0.0223 & $(0.0176)$ & -0.0227 & $(0.0158)$ & -0.0215 & $(0.0142)$ \\
\hline White & 0.0299 & $(0.0191)$ & $0.0483^{* *}$ & $(0.0221)$ & 0.00443 & $(0.00839)$ \\
\hline Black & -0.0101 & $(0.0354)$ & 0.0420 & $(0.0349)$ & 0.00407 & $(0.0102)$ \\
\hline Hispanic & -0.0172 & $(0.0118)$ & $-0.0408^{* * *}$ & $(0.0130)$ & -0.0102 & $(0.00767)$ \\
\hline High School Diploma & -0.00898 & $(0.0190)$ & $-0.0436^{* * *}$ & $(0.0135)$ & $-0.0302^{* *}$ & $(0.0121)$ \\
\hline Public Assistance & $0.0705^{* *}$ & $(0.0301)$ & $0.0942^{* * *}$ & $(0.0285)$ & $0.0703^{* * *}$ & $(0.0206)$ \\
\hline Unemployed & $0.0446^{*}$ & $(0.0236)$ & -0.00560 & $(0.0216)$ & 0.0122 & $(0.0148)$ \\
\hline \multicolumn{7}{|l|}{ SUMMARY STATISTICS } \\
\hline Outcome Mean & 0.0127 & & 0.0127 & & 0.0127 & \\
\hline Outcome SD & 0.391 & & 0.391 & & 0.391 & \\
\hline \multicolumn{7}{|l|}{ MODEL PARAMETERS } \\
\hline Fixed Effects & None & & State & & County & \\
\hline \multicolumn{7}{|l|}{ Model Statistics } \\
\hline No. of Observations & 157160 & & 157160 & & 157115 & \\
\hline No. of Clusters & 2598 & & 2598 & & 2553 & \\
\hline $\mathrm{R}^{2}$ & 0.0106 & & 0.0261 & & 0.0775 & \\
\hline
\end{tabular}

Notes: Outcome of interest is log difference in device traffic through protest site CBG relative to one month base period. Each column presents OLS coefficients with varying fixed effects. See table notation for additional details. Standard errors are clustered at the county-level in parentheses to right of coefficient estimate; ${ }^{* * *} p<0.01,{ }^{* *} p<0.05,{ }^{*} p<0.1$. 


\section{Online Appendix}

\section{Ethical Considerations}

The data used for this paper was aggregated to the Census Block Group (CBG) level from anonymized individual device data. The authors were not able to observe individual devices. To enhance privacy, SafeGraph excludes census block group information if fewer than five devices visited an establishment in a month from a given census block group. Thus, at no point in the analysis would it have been possible to identify particular individuals. This use case complies with the standard set by the United States Census Bureau's disclosure avoidance threshold. This threshold constrains public release of data at a level more granular than the CBG. This is the geographic resolution of the data we study. All the raw data underlying the mobile device data and the Parler data was retained with the explicit compliance of the platform users who generated it.

\section{Data and Code}

A thorough data description is provided in the main text. An overview of the outcomes and regressors is included in Table SI-1. Summary statistics are provided in Table SI-2, The following software packages and books were used in the data analysis: Stata: Correia (2016); R: R Core Team (2020), Dowle and Srinivasan (2020), Wickham et al. (2020), Wickham (2016), Grolemund and Wickham (2011), Wickham and Bryan (2019), Bivand, Keitt and Rowlingson (2019), Bivand et al. (2013), Pebesma (2018), Kahle and Wickham (2013), Wickham et al. (2019), Hijmans (2019), code by Richard A. Becker, version by Ray Brownrigg. Enhancements by Thomas P Minka and Deckmyn. (2018).

\section{Acknowledgements}

The authors thank SafeGraph for providing free access to their data for this research. 


\section{Supplemental Information}

Figure SI-1: Potential Protest Sites Based on Device Surges on Jan 6, 2021 With Lower Lambda Threshold

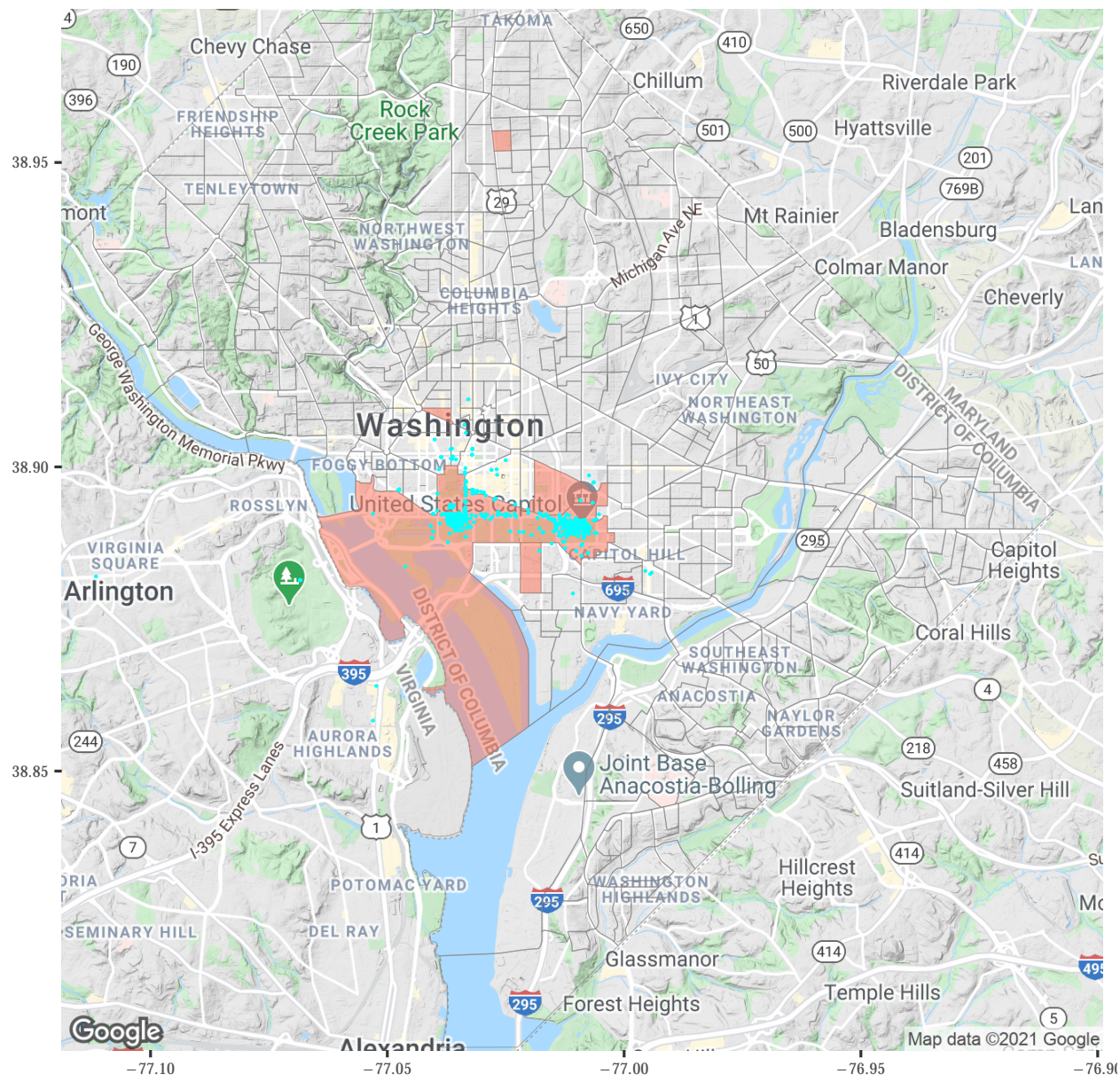

Notes:

${ }^{1}$ Polygons with red fill indicate census block groups (CBGs) for which the ratio of the number of estimated visitors on Jan 6 to the average number of visitors to the same CBG in the week prior $>250$. This replicates Figure 1 using a lower threshold. Gray lines indicate CBG polygon borders for all of DC.

${ }^{2}$ Cyan-colored dots indicate recording locations of videos uploaded to social-media website Parler on Jan 6. 
Figure SI-2: Illustration of adjacency measures for calculation of political isolation measure.

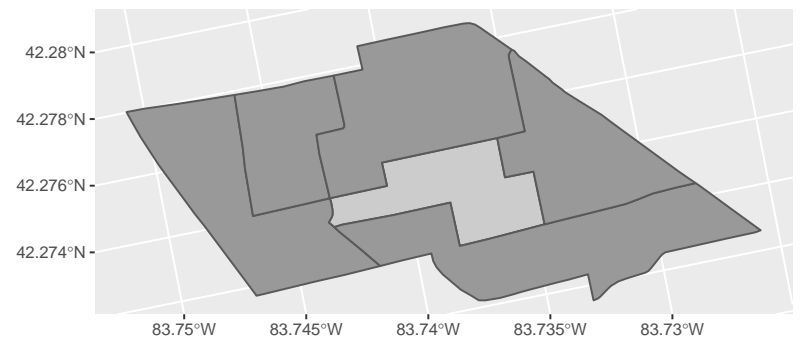

(a) Queen's case adjacency

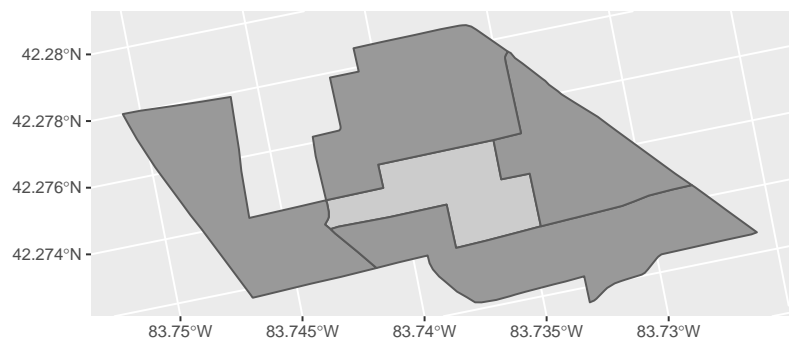

(b) Rook's case adjacency

Notes: the figures show the CBGs that are adjacent to a given CBG (illustrated for FIPS 261614002003) according to two different adjacency measures: queen's case (a) and rook's case (b). We rely on the queen's case adjacency since this more validly captures the theoretical construct we attempt to study: the communities surrounding a given origin location. 
Figure SI-3: Distribution of Trump vote share across varying measures of political isolation demonstrating common support for estimated marginal effects.

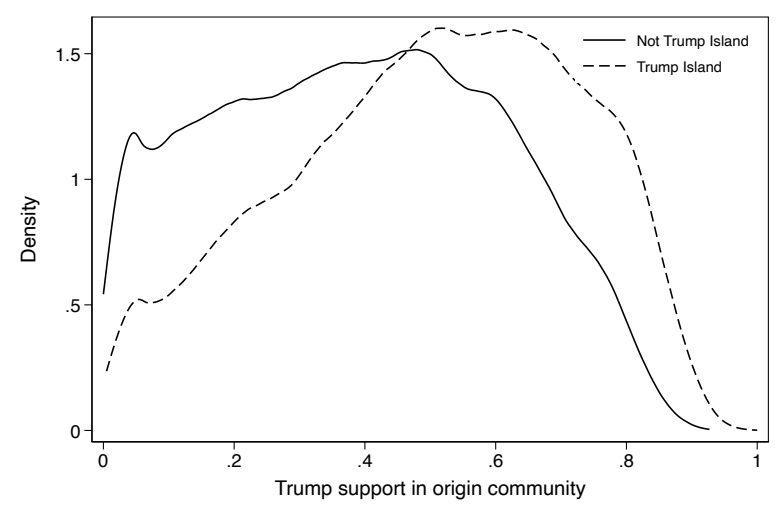

(a) Binary

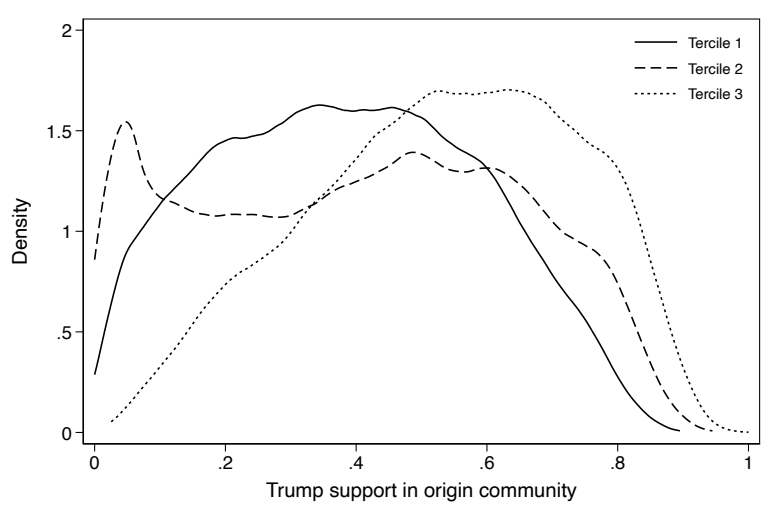

(b) Tercile-Based

Notes: the figures show the distribution of Trump support under two alternative measures of political isolation: difference exceeds zero (a) (more Trump support in origin than surrounding communities) and terciles of the isolation measures (b) (continuous difference between Trump support in origin and surrounding areas). (a) is the main specification; (b) is introduced in Table SI-3. 
Table SI-1: Description of Variables

\begin{tabular}{|c|c|c|}
\hline Variable & Description & Source \\
\hline \multicolumn{3}{|l|}{ OUTCOME VARIABLES } \\
\hline Protester count (est.) & $\begin{array}{l}\text { Raw number of devices from CBG to Capitol CBG, mul- } \\
\text { tiplied by ratio of CBG population in census to number } \\
\text { of devices residing in } \mathrm{CBG}\end{array}$ & SafeGraph \\
\hline Protester $(=1)$ & $\begin{array}{l}\text { Dummy for whether anyone from CBG went to Capitol } \\
\text { CBG on Jan } 6\end{array}$ & SafeGraph \\
\hline \multicolumn{3}{|l|}{ POLITICAL VARIABLES } \\
\hline Distance to Proud Boys & $\begin{array}{l}\text { Distance between lat-long centroid of CBG and lat-long } \\
\text { centroid of nearest local Proud Boys chapter }\end{array}$ & Southern Poverty Law Center \\
\hline Parler count & $\begin{array}{l}\text { Number of Parler videos posted in CBG since November } \\
3,2020\end{array}$ & Parler data breach \\
\hline Island & $\begin{array}{l}\text { Dummy for whether Trump neighbor share } \leq \text { Trump vote } \\
\text { share }\end{array}$ & Voting and Election Science Team \\
\hline Trump neighbor share & $\begin{array}{l}\text { Total Trump votes / total votes cast in neighboring CBGs } \\
\text { (queen adjacency) of each CBG }\end{array}$ & Voting and Election Science Team \\
\hline Trump vote share & $\begin{array}{l}\text { Share of votes in CBG that went to Donald Trump in } \\
2016 \text { Presidential Election }\end{array}$ & Voting and Election Science Team \\
\hline \multicolumn{3}{|l|}{ DEMOGRAPHIC VARIABLES } \\
\hline Male & Share of people in CBG that are male & $2016 \mathrm{ACS}$ \\
\hline Education: high school & $\begin{array}{l}\text { Share of people in CBG that have at least a high school } \\
\text { degree }\end{array}$ & 2016 ACS \\
\hline Median household income & Median household income of households in CBG & $2016 \mathrm{ACS}$ \\
\hline Population & Estimate of population residing in $\mathrm{CBG}$ & 2016 ACS \\
\hline Public assistance & $\begin{array}{l}\text { Share of people in CBG that received public assistance in } \\
2016\end{array}$ & $2016 \mathrm{ACS}$ \\
\hline Race: white & Share of people in CBG that are white & $2016 \mathrm{ACS}$ \\
\hline Race: black & Share of people in CBG that are black & 2016 ACS \\
\hline Race: hispanic & Share of people in CBG that are hispanic & $2016 \mathrm{ACS}$ \\
\hline Unemployed & $\begin{array}{l}\text { Share of people in CBG } 16 \text { years and older that are un- } \\
\text { employed }\end{array}$ & 2016 ACS \\
\hline
\end{tabular}

Notes: all variable are at the CBG level. 
Table SI-2: Summary Statistics

\begin{tabular}{|c|c|c|c|c|c|c|c|}
\hline Statistic & $\mathrm{N}$ & Mean & St. Dev. & Min & $\operatorname{Pctl}(25)$ & $\operatorname{Pctl}(75)$ & Max \\
\hline Protester count (est.) & 219,334 & 0.443 & 4.288 & 0 & 0 & 0 & 871 \\
\hline Protester $(=1)$ & 219,334 & 0.018 & 0.134 & 0 & 0 & 0 & 1 \\
\hline Distance to Proud Boys (Km) & 219,076 & 231.091 & 340.503 & 0.025 & 47.046 & 298.808 & $4,170.193$ \\
\hline Parler count & 219,334 & 0.241 & 2.596 & 0 & 0 & 0 & 495 \\
\hline Island & 161,642 & 0.462 & 0.499 & 0.000 & 0.000 & 1.000 & 1.000 \\
\hline Trump neighbor share & 161,645 & 0.446 & 0.215 & 0.004 & 0.280 & 0.618 & 0.944 \\
\hline Trump vote share & 161,643 & 0.440 & 0.225 & 0.000 & 0.262 & 0.618 & 1.000 \\
\hline Education: high school & 218,568 & 0.862 & 0.124 & 0.000 & 0.806 & 0.953 & 1.000 \\
\hline Male & 218,601 & 0.490 & 0.062 & 0.000 & 0.456 & 0.524 & 1.000 \\
\hline Median household income & 213,153 & $60,375.480$ & $33,393.060$ & $2,499.000$ & $37,813.000$ & $74,457.000$ & $250,001.000$ \\
\hline Population & 219,076 & $1,467.541$ & 926.271 & 0.000 & 895.000 & $1,799.000$ & $47,043.000$ \\
\hline Public assistance & 218,313 & 0.030 & 0.045 & 0.000 & 0.000 & 0.041 & 1.000 \\
\hline Race: white & 218,601 & 0.738 & 0.265 & 0.000 & 0.611 & 0.944 & 1.000 \\
\hline Race: black & 218,601 & 0.133 & 0.229 & 0.000 & 0.000 & 0.143 & 1.000 \\
\hline Race: hispanic & 218,601 & 0.165 & 0.238 & 0.000 & 0.012 & 0.206 & 1.000 \\
\hline Unemployed & 218,467 & 0.081 & 0.074 & 0.000 & 0.031 & 0.109 & 1.000 \\
\hline
\end{tabular}


Table SI-3: Factors associated with participation in the 'March to Save America' event using a tertiary measure of political isolation, log differences

\begin{tabular}{|c|c|c|c|c|c|c|}
\hline \multirow[b]{2}{*}{ TRUMP } & \multicolumn{6}{|c|}{ Protesters $(\log \Delta), 1 m$} \\
\hline & & & & & & \\
\hline Trump Share & $0.126^{* * *}$ & $(0.0215)$ & $0.134^{* * *}$ & $(0.0251)$ & $0.108^{* * *}$ & $(0.0138)$ \\
\hline Trump: Origin vs. Adj Terciles $=2$ & -0.0198 & $(0.0146)$ & $-0.0191^{*}$ & $(0.0107)$ & -0.00302 & $(0.00443)$ \\
\hline Trump: Origin vs. Adj Terciles $=3$ & $-0.0253^{* * *}$ & $(0.00727)$ & $-0.0248^{* * *}$ & $(0.00618)$ & $-0.0158^{* * *}$ & $(0.00594)$ \\
\hline Trump: Origin vs. Adj Terciles $=2 \times$ Trump Share & 0.0364 & $(0.0254)$ & 0.0309 & $(0.0189)$ & 0.00531 & $(0.0105)$ \\
\hline Trump: Origin vs. Adj Terciles $=3 \times$ Trump Share & $0.0503^{* * *}$ & $(0.0135)$ & $0.0458^{* * *}$ & $(0.0120)$ & $0.0308^{* * *}$ & $(0.0118)$ \\
\hline \multicolumn{7}{|l|}{ Census Block Group } \\
\hline Dist. to Proud Boys (Log) & $-0.00686^{* *}$ & $(0.00271)$ & $-0.0107^{* * *}$ & $(0.00331)$ & -0.0000657 & $(0.00271)$ \\
\hline \# Parler Videos (Log) & $0.0143^{* * *}$ & $(0.00389)$ & $0.0121^{* * *}$ & $(0.00373)$ & $0.00904^{* *}$ & $(0.00365)$ \\
\hline Median HH Income (Log) & -0.0166 & $(0.0149)$ & -0.00176 & $(0.00839)$ & $0.0187^{* * *}$ & $(0.00301)$ \\
\hline \multicolumn{7}{|l|}{ SHARE OF CBG PoP: } \\
\hline Male & -0.0224 & $(0.0176)$ & -0.0229 & $(0.0158)$ & -0.0214 & $(0.0142)$ \\
\hline White & 0.0297 & $(0.0192)$ & $0.0485^{* *}$ & $(0.0222)$ & 0.00438 & $(0.00842)$ \\
\hline Black & -0.0108 & $(0.0350)$ & 0.0424 & $(0.0346)$ & 0.00376 & $(0.0100)$ \\
\hline Hispanic & -0.0177 & $(0.0120)$ & $-0.0412^{* * *}$ & $(0.0132)$ & -0.0104 & $(0.00767)$ \\
\hline High School Diploma & -0.00905 & $(0.0188)$ & $-0.0438^{* * *}$ & $(0.0136)$ & $-0.0303^{* *}$ & $(0.0121)$ \\
\hline Public Assistance & $0.0720^{* *}$ & $(0.0307)$ & $0.0943^{* * *}$ & $(0.0288)$ & $0.0700^{* * *}$ & $(0.0206)$ \\
\hline Unemployed & $0.0451^{*}$ & $(0.0237)$ & -0.00538 & $(0.0215)$ & 0.0122 & $(0.0148)$ \\
\hline \multicolumn{7}{|l|}{$\overline{\text { SUMMARY STATISTICS }}$} \\
\hline Outcome Mean & 0.0127 & & 0.0127 & & 0.0127 & \\
\hline Outcome SD & 0.391 & & 0.391 & & 0.391 & \\
\hline \multicolumn{7}{|l|}{ MODEL PARAMETERS } \\
\hline Fixed Effects & None & & State & & County & \\
\hline \multicolumn{7}{|l|}{ MODEL STATISTICS } \\
\hline No. of Observations & 157159 & & 157159 & & 157114 & \\
\hline No. of Clusters & 2598 & & 2598 & & 2553 & \\
\hline $\mathrm{R}^{2}$ & 0.0106 & & 0.0262 & & 0.0775 & \\
\hline
\end{tabular}

Notes: Outcome of interest is log difference in device traffic through protest site CBG relative to one month base period. Each column presents OLS coefficients with varying fixed effects. See table notation for additional details. Base terms and marginal effects are reported for a tertiary specification of the political isolation measure, where the distribution of the difference between community and adjacent community support for Trump in 2016 is split into terciles. Standard errors are clustered at the countylevel in parentheses to right of coefficient estimate; ${ }^{* * *} p<0.01,{ }^{* *} p<0.05,{ }^{*} p<0.1$. 
Table SI-4: Factors associated with participation in the 'March to Save America' event, extensive margin (participation $=1$ )

\begin{tabular}{|c|c|c|c|c|c|c|}
\hline \multirow[b]{2}{*}{ TRUMP } & \multicolumn{6}{|c|}{ Protester $(=1)$} \\
\hline & & & & & & \\
\hline Trump Share & $0.0277^{* * *}$ & $(0.00390)$ & $0.0192^{* * *}$ & $(0.00348)$ & $0.0265^{* * *}$ & $(0.00422)$ \\
\hline Island $=1$ & -0.00132 & $(0.00112)$ & -0.00195 & $(0.00132)$ & $-0.00277^{*}$ & $(0.00153)$ \\
\hline Island $=1 \times$ Trump Share & $0.00650^{* *}$ & $(0.00269)$ & $0.00711^{* *}$ & $(0.00287)$ & $0.00812^{* *}$ & $(0.00316)$ \\
\hline \multicolumn{7}{|l|}{ Census Block Group } \\
\hline Dist. to Proud Boys (Log) & 0.0000995 & $(0.000625)$ & 0.000294 & $(0.000582)$ & -0.000502 & $(0.00105)$ \\
\hline \# Parler Videos (Log) & $0.00320^{* *}$ & $(0.00128)$ & $0.00394^{* * *}$ & $(0.00127)$ & $0.00281^{* *}$ & $(0.00126)$ \\
\hline Median HH Income (Log) & $0.0180^{* * *}$ & $(0.00356)$ & $0.0121^{* * *}$ & $(0.00164)$ & $0.00655^{* * *}$ & $(0.00106)$ \\
\hline \multicolumn{7}{|l|}{ SHARE OF CBG POP: } \\
\hline Male & $-0.0145^{* * *}$ & $(0.00472)$ & -0.00567 & $(0.00461)$ & -0.00507 & $(0.00466)$ \\
\hline White & $0.0106^{* * *}$ & $(0.00380)$ & -0.00149 & $(0.00303)$ & $0.00586^{* *}$ & $(0.00274)$ \\
\hline Black & $0.0316^{* * *}$ & $(0.00939)$ & -0.0105 & $(0.00685)$ & 0.000908 & $(0.00432)$ \\
\hline Hispanic & $-0.0168^{* * *}$ & $(0.00306)$ & -0.00526 & $(0.00339)$ & $-0.00798^{* * *}$ & $(0.00249)$ \\
\hline High School Diploma & $-0.0229^{* * *}$ & $(0.00473)$ & 0.00166 & $(0.00430)$ & -0.00164 & $(0.00379)$ \\
\hline Public Assistance & -0.00176 & $(0.00723)$ & $0.0217^{* *}$ & $(0.00853)$ & $0.0154^{* *}$ & $(0.00751)$ \\
\hline Unemployed & -0.00501 & $(0.00593)$ & 0.00559 & $(0.00540)$ & 0.00136 & $(0.00488)$ \\
\hline Constant & $-0.192^{* * *}$ & $(0.0372)$ & $-0.138^{* * *}$ & $(0.0201)$ & $-0.0794^{* * *}$ & $(0.0127)$ \\
\hline \multicolumn{7}{|l|}{ SUMMARY STATISTICS } \\
\hline Outcome Mean & 0.0181 & & 0.0181 & & 0.0181 & \\
\hline Outcome SD & 0.133 & & 0.133 & & 0.133 & \\
\hline \multicolumn{7}{|l|}{ MODEL PARAMETERS } \\
\hline Fixed Effects & None & & State & & County & \\
\hline \multicolumn{7}{|l|}{ MOdEL Statistics } \\
\hline No. of Observations & 157160 & & 157160 & & 157115 & \\
\hline No. of Clusters & 2598 & & 2598 & & 2553 & \\
\hline $\mathrm{R}^{2}$ & 0.0172 & & 0.0383 & & 0.0704 & \\
\hline
\end{tabular}

Notes: Outcome of interest is the extensive margin of participation (at least one device from origin CBG present at protest site on protest date). Each column presents LPM coefficients with varying fixed effects. See table notation for additional details. Standard errors are clustered at the county-level in parentheses to right of coefficient estimate; ${ }^{* * *} p<0.01,{ }^{* *} p<0.05,{ }^{*} p<0.1$. 
Table SI-5: Factors associated with participation in the 'March to Save America' event, inverse hyperbolic differences

\begin{tabular}{|c|c|c|c|c|c|c|}
\hline \multirow{2}{*}{ TRUMP } & \multicolumn{6}{|c|}{ Protesters $(A \sinh \Delta), 1 m$} \\
\hline & & & & & & \\
\hline Trump Share & $0.177^{* * *}$ & $(0.0306)$ & $0.183^{* * *}$ & $(0.0351)$ & $0.131^{* * *}$ & $(0.0156)$ \\
\hline Island $=1$ & $-0.0211^{*}$ & $(0.0115)$ & $-0.0209^{* *}$ & $(0.00900)$ & $-0.0136^{* *}$ & $(0.00649)$ \\
\hline Island $=1 \times$ Trump Share & $0.0454^{* *}$ & $(0.0197)$ & $0.0422^{* * *}$ & $(0.0162)$ & $0.0311^{* *}$ & $(0.0124)$ \\
\hline \multicolumn{7}{|l|}{ CEnsus Block Group } \\
\hline Dist. to Proud Boys (Log) & $-0.00892^{* *}$ & $(0.00351)$ & $-0.0138^{* * *}$ & $(0.00427)$ & 0.000244 & $(0.00336)$ \\
\hline \# Parler Videos (Log) & $0.0184^{* * *}$ & $(0.00480)$ & $0.0153^{* * *}$ & $(0.00456)$ & $0.0115^{* *}$ & $(0.00446)$ \\
\hline Median HH Income (Log) & -0.0257 & $(0.0201)$ & -0.00542 & $(0.0112)$ & $0.0228^{* * *}$ & $(0.00367)$ \\
\hline \multicolumn{7}{|l|}{ SHARE OF CBG POP: } \\
\hline Male & -0.0267 & $(0.0221)$ & -0.0283 & $(0.0194)$ & -0.0268 & $(0.0172)$ \\
\hline White & 0.0387 & $(0.0250)$ & $0.0639^{* *}$ & $(0.0290)$ & 0.00533 & $(0.0101)$ \\
\hline Black & -0.0147 & $(0.0469)$ & 0.0573 & $(0.0462)$ & 0.00460 & $(0.0125)$ \\
\hline Hispanic & -0.0196 & $(0.0152)$ & $-0.0522^{* * *}$ & $(0.0166)$ & -0.0121 & $(0.00946)$ \\
\hline High School Diploma & -0.00520 & $(0.0244)$ & $-0.0535^{* * *}$ & $(0.0168)$ & $-0.0357^{* *}$ & $(0.0147)$ \\
\hline Public Assistance & $0.0856^{* *}$ & $(0.0381)$ & $0.115^{* * *}$ & $(0.0359)$ & $0.0849^{* * *}$ & $(0.0248)$ \\
\hline Unemployed & $0.0574^{*}$ & $(0.0302)$ & -0.00856 & $(0.0277)$ & 0.0153 & $(0.0180)$ \\
\hline \multicolumn{7}{|l|}{ SUMMARY STATISTICS } \\
\hline Outcome Mean & 0.0147 & & 0.0147 & & 0.0147 & \\
\hline Outcome SD & 0.477 & & 0.477 & & 0.477 & \\
\hline \multicolumn{7}{|l|}{ MODEL PARAMETERS } \\
\hline Fixed Effects & None & & State & & County & \\
\hline \multicolumn{7}{|l|}{ MODEL STATISTICS } \\
\hline No. of Observations & 157160 & & 157160 & & 157115 & \\
\hline No. of Clusters & 2598 & & 2598 & & 2553 & \\
\hline $\mathrm{R}^{2}$ & 0.0116 & & 0.0303 & & 0.0877 & \\
\hline
\end{tabular}

Notes: Outcome of interest is inverse hyperbolic difference in device traffic through protest site CBG relative to one month base period. Each column presents OLS coefficients with varying fixed effects. See table notation for additional details. Standard errors are clustered at the county-level in parentheses to right of coefficient estimate; ${ }^{* * *} p<0.01,{ }^{* *} p<0.05,{ }^{*} p<0.1$. 
Table SI-6: Factors associated with participation in the 'March to Save America' event, log differences (two month base period)

\begin{tabular}{|c|c|c|c|c|c|c|}
\hline \multirow[b]{2}{*}{ TRUMP } & \multicolumn{6}{|c|}{ Protesters $(\log \Delta), 2 m$} \\
\hline & & & & & & \\
\hline Trump Share & $0.129^{* * *}$ & $(0.0166)$ & $0.126^{* * *}$ & $(0.0204)$ & $0.107^{* * *}$ & $(0.0123)$ \\
\hline Island $=1$ & $-0.0133^{*}$ & $(0.00770)$ & $-0.0137^{* *}$ & $(0.00681)$ & $-0.0102^{*}$ & $(0.00562)$ \\
\hline Island $=1 \times$ Trump Share & $0.0307^{* *}$ & $(0.0137)$ & $0.0294^{* *}$ & $(0.0125)$ & $0.0233^{* *}$ & $(0.0106)$ \\
\hline \multicolumn{7}{|l|}{ Census Block Group } \\
\hline Dist. to Proud Boys (Log) & $-0.00528^{* * *}$ & $(0.00176)$ & $-0.00823^{* * *}$ & $(0.00238)$ & 0.000457 & $(0.00267)$ \\
\hline \# Parler Videos (Log) & $0.0162^{* * *}$ & $(0.00369)$ & $0.0148^{* * *}$ & $(0.00363)$ & $0.0112^{* * *}$ & $(0.00357)$ \\
\hline Median HH Income (Log) & 0.00448 & $(0.00947)$ & $0.0107^{*}$ & $(0.00620)$ & $0.0218^{* * *}$ & $(0.00305)$ \\
\hline \multicolumn{7}{|l|}{ Share of CBG Pop: } \\
\hline Male & $-0.0273^{*}$ & $(0.0152)$ & -0.0207 & $(0.0150)$ & -0.0189 & $(0.0143)$ \\
\hline White & $0.0229^{*}$ & $(0.0131)$ & $0.0281^{*}$ & $(0.0165)$ & -0.000427 & $(0.00800)$ \\
\hline Black & 0.0156 & $(0.0217)$ & 0.0228 & $(0.0249)$ & 0.00321 & $(0.00979)$ \\
\hline Hispanic & $-0.0185^{* *}$ & $(0.00904)$ & $-0.0267^{* *}$ & $(0.0107)$ & -0.00619 & $(0.00724)$ \\
\hline High School Diploma & -0.0205 & $(0.0148)$ & $-0.0265^{* *}$ & $(0.0124)$ & $-0.0203^{*}$ & $(0.0115)$ \\
\hline Public Assistance & $0.0504^{* *}$ & $(0.0242)$ & $0.0846^{* * *}$ & $(0.0241)$ & $0.0619^{* * *}$ & $(0.0205)$ \\
\hline Unemployed & 0.0289 & $(0.0183)$ & -0.000411 & $(0.0175)$ & 0.00922 & $(0.0144)$ \\
\hline \multicolumn{7}{|l|}{ SUMMARY STATISTICS } \\
\hline Outcome Mean & 0.0242 & & 0.0242 & & 0.0242 & \\
\hline Outcome SD & 0.379 & & 0.379 & & 0.379 & \\
\hline \multicolumn{7}{|l|}{ MODEL PARAMETERS } \\
\hline Fixed Effects & None & & State & & County & \\
\hline \multicolumn{7}{|l|}{ MOdEL Statistics } \\
\hline No. of Observations & 157160 & & 157160 & & 157115 & \\
\hline No. of Clusters & 2598 & & 2598 & & 2553 & \\
\hline $\mathrm{R}^{2}$ & 0.00833 & & 0.0135 & & 0.0488 & \\
\hline
\end{tabular}

Notes: Outcome of interest is log difference in device traffic through protest site CBG relative to two month base period. Each column presents OLS coefficients with varying fixed effects. See table notation for additional details. Standard errors are clustered at the county-level in parentheses to right of coefficient estimate; ${ }^{* * *} p<0.01,{ }^{* *} p<0.05,{ }^{*} p<0.1$. 
Table SI-7: Factors associated with participation in the 'March to Save America' event, log differences (three month base period)

\begin{tabular}{|c|c|c|c|c|c|c|}
\hline \multirow[b]{2}{*}{ TRUMP } & \multicolumn{6}{|c|}{ Protesters $(\log \Delta), 3 m$} \\
\hline & & & & & & \\
\hline Trump Share & $0.116^{* * *}$ & $(0.0101)$ & $0.105^{* * *}$ & $(0.0136)$ & $0.106^{* * *}$ & $(0.0119)$ \\
\hline Island $=1$ & $-0.0118^{* *}$ & $(0.00567)$ & $-0.0126^{* *}$ & $(0.00571)$ & $-0.0110^{* *}$ & $(0.00527)$ \\
\hline Island $=1 \times$ Trump Share & $0.0275^{* *}$ & $(0.0107)$ & $0.0272^{* *}$ & $(0.0107)$ & $0.0237^{* *}$ & $(0.00999)$ \\
\hline \multicolumn{7}{|l|}{ Census Block Group } \\
\hline Dist. to Proud Boys (Log) & $-0.00371^{* * *}$ & $(0.00107)$ & $-0.00547^{* * *}$ & $(0.00168)$ & 0.000896 & $(0.00269)$ \\
\hline \# Parler Videos (Log) & $0.0176^{* * *}$ & $(0.00356)$ & $0.0170^{* * *}$ & $(0.00355)$ & $0.0128^{* * *}$ & $(0.00349)$ \\
\hline Median HH Income (Log) & $0.0245^{* * *}$ & $(0.00506)$ & $0.0223^{* * *}$ & $(0.00456)$ & $0.0233^{* * *}$ & $(0.00310)$ \\
\hline \multicolumn{7}{|l|}{ Share of CBG Pop: } \\
\hline Male & $-0.0370^{* * *}$ & $(0.0134)$ & $-0.0237^{*}$ & $(0.0139)$ & -0.0214 & $(0.0139)$ \\
\hline White & $0.0161^{*}$ & $(0.00834)$ & 0.00731 & $(0.0114)$ & -0.00477 & $(0.00783)$ \\
\hline Black & $0.0391^{* * *}$ & $(0.00960)$ & 0.00143 & $(0.0156)$ & 0.00135 & $(0.0102)$ \\
\hline Hispanic & $-0.0186^{* * *}$ & $(0.00711)$ & -0.0131 & $(0.00955)$ & -0.00338 & $(0.00684)$ \\
\hline High School Diploma & $-0.0308^{* *}$ & $(0.0124)$ & -0.0105 & $(0.0123)$ & -0.0123 & $(0.0112)$ \\
\hline Public Assistance & $0.0345^{*}$ & $(0.0209)$ & $0.0799^{* * *}$ & $(0.0224)$ & $0.0583^{* * *}$ & $(0.0213)$ \\
\hline Unemployed & 0.0105 & $(0.0143)$ & 0.00107 & $(0.0148)$ & 0.00246 & $(0.0138)$ \\
\hline \multicolumn{7}{|l|}{ SUMMARY STATISTICS } \\
\hline Outcome Mean & 0.0336 & & 0.0336 & & 0.0336 & \\
\hline Outcome SD & 0.372 & & 0.372 & & 0.372 & \\
\hline \multicolumn{7}{|l|}{ MODEL PARAMETERS } \\
\hline Fixed Effects & None & & State & & County & \\
\hline \multicolumn{7}{|l|}{ MODEL Statistics } \\
\hline No. of Observations & 157160 & & 157160 & & 157115 & \\
\hline No. of Clusters & 2598 & & 2598 & & 2553 & \\
\hline $\mathrm{R}^{2}$ & 0.00722 & & 0.0101 & & 0.0355 & \\
\hline
\end{tabular}

Notes: Outcome of interest is log difference in device traffic through protest site CBG relative to three month base period. Each column presents OLS coefficients with varying fixed effects. See table notation for additional details. Standard errors are clustered at the county-level in parentheses to right of coefficient estimate; ${ }^{* * *} p<0.01,{ }^{* *} p<0.05,{ }^{*} p<0.1$. 
Table SI-8: Factors associated with participation in the 'March to Save America' event, log differences (including Washington, D.C. origin CBGs)

\begin{tabular}{|c|c|c|c|c|c|c|}
\hline \multirow[b]{2}{*}{ TRUMP } & \multicolumn{6}{|c|}{ Protesters $(\log \Delta), 1 m$} \\
\hline & & & & & & \\
\hline Trump Share & $0.169^{* * *}$ & $(0.0376)$ & $0.151^{* * *}$ & $(0.0279)$ & $0.119^{* * *}$ & $(0.0185)$ \\
\hline Island $=1$ & $-0.0160^{*}$ & $(0.00903)$ & $-0.0148^{* *}$ & $(0.00734)$ & $-0.00954^{*}$ & $(0.00550)$ \\
\hline Island $=1 \times$ Trump Share & $0.0326^{* *}$ & $(0.0158)$ & $0.0307^{* *}$ & $(0.0133)$ & $0.0222^{* *}$ & $(0.0106)$ \\
\hline \multicolumn{7}{|l|}{ Census Block Group } \\
\hline Dist. to Proud Boys (Log) & $-0.00852^{* * *}$ & $(0.00322)$ & $-0.0106^{* * *}$ & $(0.00324)$ & -0.000461 & $(0.00281)$ \\
\hline \# Parler Videos (Log) & $0.0156^{* * *}$ & $(0.00405)$ & $0.0124^{* * *}$ & $(0.00372)$ & $0.00919^{* *}$ & $(0.00365)$ \\
\hline Median HH Income (Log) & -0.0250 & $(0.0165)$ & -0.00218 & $(0.00843)$ & $0.0182^{* * *}$ & $(0.00302)$ \\
\hline \multicolumn{7}{|l|}{ Share of CBG PoP: } \\
\hline Male & -0.0214 & $(0.0176)$ & -0.0262 & $(0.0160)$ & $-0.0248^{*}$ & $(0.0144)$ \\
\hline White & 0.0166 & $(0.0234)$ & $0.0466^{* *}$ & $(0.0221)$ & 0.00275 & $(0.00842)$ \\
\hline Black & -0.0326 & $(0.0411)$ & 0.0517 & $(0.0358)$ & 0.0179 & $(0.0167)$ \\
\hline Hispanic & -0.0139 & $(0.0126)$ & $-0.0389^{* * *}$ & $(0.0130)$ & -0.00815 & $(0.00780)$ \\
\hline High School Diploma & -0.00670 & $(0.0193)$ & $-0.0432^{* * *}$ & $(0.0135)$ & $-0.0309^{* *}$ & $(0.0120)$ \\
\hline Public Assistance & 0.0520 & $(0.0359)$ & $0.0967^{* * *}$ & $(0.0286)$ & $0.0730^{* * *}$ & $(0.0206)$ \\
\hline Unemployed & $0.0456^{*}$ & $(0.0238)$ & -0.00463 & $(0.0215)$ & 0.0133 & $(0.0148)$ \\
\hline \multicolumn{7}{|l|}{ SUMMARY STATISTICS } \\
\hline Outcome Mean & 0.00952 & & 0.00952 & & 0.00951 & \\
\hline Outcome SD & 0.402 & & 0.402 & & 0.402 & \\
\hline \multicolumn{7}{|l|}{ MODEL PARAMETERS } \\
\hline Fixed Effects & None & & State & & County & \\
\hline \multicolumn{7}{|l|}{ Model Statistics } \\
\hline No. of Observations & 157591 & & 157591 & & 157546 & \\
\hline No. of Clusters & 2599 & & 2599 & & 2554 & \\
\hline $\mathrm{R}^{2}$ & 0.0133 & & 0.0480 & & 0.0962 & \\
\hline
\end{tabular}

Notes: Outcome of interest is log difference in device traffic through protest site CBG relative to one month base period. Sample includes Washington, D.C. origin CBGs. Each column presents OLS coefficients with varying fixed effects. See table notation for additional details. Standard errors are clustered at the county-level in parentheses to right of coefficient estimate; ${ }^{* * *} p<0.01,{ }^{* *} p<0.05$, $* p<0.1$. 
Table SI-9: Factors associated with participation in the 'March to Save America' event, log differences, accounting for arbitrary spatial clustering

\begin{tabular}{|c|c|c|c|c|c|c|}
\hline \multirow[b]{2}{*}{ TRUMP } & \multicolumn{6}{|c|}{ Protesters $(\log \Delta), 1 m$} \\
\hline & & & & & & \\
\hline Trump Share & $0.139^{* * *}$ & $(0.0437)$ & $0.143^{* * *}$ & $(0.0462)$ & $0.106^{* * *}$ & $(0.0135)$ \\
\hline Island & $-0.0164^{* *}$ & $(0.00708)$ & $-0.0163^{* * *}$ & $(0.00546)$ & $-0.0109^{* * *}$ & $(0.00411)$ \\
\hline Island $=1 \times$ Trump Share & $0.0358^{* * *}$ & $(0.0116)$ & $0.0335^{* * *}$ & $(0.00940)$ & $0.0251^{* * *}$ & $(0.00820)$ \\
\hline \multicolumn{7}{|l|}{ Census Block Group } \\
\hline Dist. to Proud Boys (Log) & -0.00675 & $(0.00518)$ & -0.0105 & $(0.00648)$ & 0.0000707 & $(0.00272)$ \\
\hline \# Parler Videos (Log) & $0.0144^{* * *}$ & $(0.00391)$ & $0.0122^{* * *}$ & $(0.00313)$ & $0.00909^{* * *}$ & $(0.00294)$ \\
\hline Median HH Income (Log) & -0.0171 & $(0.0328)$ & -0.00219 & $(0.0159)$ & $0.0186^{* * *}$ & $(0.00317)$ \\
\hline \multicolumn{7}{|l|}{ SHARE OF CBG POP: } \\
\hline Male & -0.0223 & $(0.0143)$ & -0.0227 & $(0.0139)$ & -0.0215 & $(0.0142)$ \\
\hline White & 0.0299 & $(0.0237)$ & 0.0483 & $(0.0357)$ & 0.00443 & $(0.00876)$ \\
\hline Black & -0.0101 & $(0.0353)$ & 0.0420 & $(0.0407)$ & 0.00407 & $(0.00935)$ \\
\hline Hispanic & $-0.0172^{*}$ & $(0.00968)$ & $-0.0408^{* *}$ & $(0.0200)$ & -0.0102 & $(0.00943)$ \\
\hline High School Diploma & -0.00898 & $(0.0308)$ & $-0.0436^{* *}$ & $(0.0183)$ & $-0.0302^{* *}$ & $(0.0131)$ \\
\hline Public Assistance & 0.0705 & $(0.0459)$ & $0.0942^{* * *}$ & $(0.0249)$ & $0.0703^{* * *}$ & $(0.0209)$ \\
\hline Unemployed & 0.0446 & $(0.0355)$ & -0.00560 & $(0.0181)$ & 0.0122 & $(0.0192)$ \\
\hline \multicolumn{7}{|l|}{ SUMMARY STATISTICS } \\
\hline \multicolumn{7}{|l|}{$\begin{array}{l}\text { Outcome Mean } \\
\text { Outcome SD }\end{array}$} \\
\hline \multicolumn{7}{|l|}{ Outcome SD } \\
\hline \multirow{2}{*}{\multicolumn{7}{|c|}{$\begin{array}{l}\text { MODEL PARAMETERS } \\
\text { Fixed Effects }\end{array}$}} \\
\hline & & & & & & \\
\hline \multicolumn{7}{|l|}{ MODEL StATISTICS } \\
\hline No. of Observations & 157160 & & 157160 & & 157160 & \\
\hline \multicolumn{7}{|l|}{ No. of Clusters } \\
\hline $\mathrm{R}^{2}$ & 0.0106 & & 0.00837 & & 0.00283 & \\
\hline
\end{tabular}

Notes: Outcome of interest is log difference in device traffic through protest site CBG relative to one month base period. Each column presents OLS coefficients with varying fixed effects. See table notation for additional details. Standard errors are clustered to account for arbitrary spatial dependence within 50 kilometers of the community using the method introduced in Colella et al. (2019), presented in parentheses to right of coefficient estimate; ${ }^{* *} p<0.01,{ }^{* *} p<0.05,{ }^{*} p<0.1$. 


\section{Media coverage}

Table SI-10: Journalistic and slanted coverage of 'March to Save America' protest and riot participants, January 6, 2021

\begin{tabular}{|c|c|c|c|}
\hline Characteristic & $\begin{array}{ll}\text { Source } 1 \\
\end{array}$ & Source 2 & Source 3 \\
\hline Facing crim. charges & $\begin{array}{l}\text { "The Associated Press reviewed social media } \\
\text { posts, voter registrations, court files and other } \\
\text { public records for more than } 120 \text { people either } \\
\text { facing criminal charges related to the Jan. } 6 \\
\text { unrest or who, going maskless amid the } \\
\text { pandemic, were later identified through } \\
\text { photographs and videos taken during the melee." } \\
\text { (AP) }\end{array}$ & $\begin{array}{l}\text { "Dozens of people on a terrorist watch list were } \\
\text { in Washington for pro-Trump events Jan. } 6 \text {, a } \\
\text { day that ended in a chaotic crime rampage when } \\
\text { a violent mob stormed the U.S. Capitol, } \\
\text { according to people familiar with evidence } \\
\text { gathered in the FBI's investigation." (WashPo) }\end{array}$ & \\
\hline QAnon & $\begin{array}{l}\text { The insurrectionist mob that showed up at the } \\
\text { president's behest and stormed the U.S. Capitol } \\
\text { was overwhelmingly made up of longtime Trump } \\
\text { supporters, including Republican Party officials, } \\
\text { GOP political donors, far-right militants, white } \\
\text { supremacists, members of the military and } \\
\text { adherents of the QAnon myth that the } \\
\text { government is secretly controlled by a cabal of } \\
\text { Satan-worshiping pedophile cannibals." [AP) }\end{array}$ & $\begin{array}{l}\text { "Chansley of Arizona, who the DOJ says is also } \\
\text { known as Jake Angeli, is identified as the } \\
\text { so-called "QAnon shaman" who was seen in } \\
\text { several photos - most memorably standing at } \\
\text { the Senate dais - with his face painted and } \\
\text { wearing a bearskin headdress." [NPR) }\end{array}$ & $\begin{array}{l}\text { "Much is still unknown about the planning and } \\
\text { financing of the storming of the Capitol, aiming } \\
\text { to challenge Mr. Trump's electoral defeat. What } \\
\text { is clear is that it was driven, in part, by a largely } \\
\text { ad hoc network of low-budget agitators, including } \\
\text { far-right militants, Christian conservatives and } \\
\text { ardent adherents of the QAnon conspiracy } \\
\text { theory." }\end{array}$ \\
\hline Military & $\begin{array}{l}\text { "In fact, an NPR analysis has found that nearly } \\
1 \text { in } 5 \text { people charged over their alleged } \\
\text { involvement in the attack on the U.S. Capitol } \\
\text { appear to have a military history." (NPR) }\end{array}$ & $\begin{array}{l}\text { "As total federal arrests in the Capitol riot grow } \\
\text { past 100, Mr. Fracker is one of at least } 18 \text { current } \\
\text { and former police officers, firefighters and military } \\
\text { members who have been charged as of Friday } \\
\text { according to a Wall Street Journal tally." (WSJ) }\end{array}$ & \\
\hline Far-right groups & $\begin{array}{l}\text { "The insurrectionist mob also included members } \\
\text { of the neofascist group known as the Proud } \\
\text { Boys." AP. }\end{array}$ & $\begin{array}{l}\text { "Members of several far-right groups, including } \\
\text { the Proud Boys, Oath Keepers and Three } \\
\text { Percenters, were present." (MSN) }\end{array}$ & $\begin{array}{l}\text { "Proud Boys members participated in last week's } \\
\text { protests, and FBI agents are taking a close look } \\
\text { at what roles, if any, the group's adherents may } \\
\text { have had in organizing, directing or carrying out } \\
\text { violence, according to people familiar with the } \\
\text { matter." (WashPo) }\end{array}$ \\
\hline Police officers & $\begin{array}{l}\text { Police officers and at least one police chief from } \\
\text { departments across the United States are facing } \\
\text { termination, suspension or other discipline for } \\
\text { their proximity to or alleged involvement in a } \\
\text { chaotic gathering in Washington on Wednesday." } \\
\text { (WashPo) }\end{array}$ & $\begin{array}{l}\text { "According to a tracker on The Appeal, as of } \\
\text { Jan. } 15 \text { a total of } 29 \text { law enforcement officers or } \\
\text { officials are suspected of participating in } \\
\text { President Trump's Jan. } 6 \text { rally, and/or joining } \\
\text { the crowds storming the U.S. Capitol later that } \\
\text { day. In addition, the FBI has identified more } \\
\text { than } 200 \text { rioters who were part of the } \\
\text { insurrection." (Time) }\end{array}$ & $\begin{array}{l}\text { "'Several" U.S. Capitol Police officers were } \\
\text { suspended and at least } 10 \text { more are under } \\
\text { investigation over the deadly pro-Trump } \\
\text { insurrection last week, officials said Monday." } \\
\text { (NBCNews) }\end{array}$ \\
\hline
\end{tabular}


Table SI-10: Journalistic and slanted coverage of 'March to Save America' protest and riot participants, January 6, 2021

\begin{tabular}{|c|c|c|c|}
\hline Characteristic & Source 1 & $\begin{array}{l}\text { Source } 2 \\
\end{array}$ & Source 3 \\
\hline White & $\begin{array}{l}\text { "a largely white crowd, many of them armed } \\
\text { with bats, shields and chemical spray; some } \\
\text { carried Confederate flags and wore costumes of } \\
\text { fur and horns inspired by QAnon." [NYTimes) }\end{array}$ & $\begin{array}{l}\text { "The demographic point to which many have } \\
\text { turned next is race, an obvious choice given } \\
\text { Trump's involvement. It's also, conveniently, } \\
\text { identifiable in any photo: The crowd that overran } \\
\text { the Capitol was overwhelmingly white, perhaps } \\
\text { even more than Trump voters generally." } \\
\text { (TheWeek). }\end{array}$ & \\
\hline Mostly men & $\begin{array}{l}\text { "they were mostly men but there were women, } \\
\text { too." (NYTimes) }\end{array}$ & $\begin{array}{l}\text { "When an overwhelmingly white, male mob } \\
\text { rampaged the Capitol last week armed with guns } \\
\text { and zip ties, attacking police with metal pipes } \\
\text { and erecting a gallows, the nation reeled in } \\
\text { horror." (USAToday). }\end{array}$ & $\begin{array}{l}\text { "They were men (and, yes, some women) lost in } \\
\text { a modern world that no longer assumed they } \\
\text { come first." (TheAtlantic). }\end{array}$ \\
\hline Christian & $\begin{array}{l}\text { "It was Christian nationalism, resourced from } \\
\text { white evangelicalism, prosperity gospel hucksters, } \\
\text { and the charismatic movement's characteristic } \\
\text { confidence in individual ability to hear from God. } \\
\text { (Little of that is "respectable," by the way. } \\
\text { "Holy rollers" is not a term of respect, as } \\
\text { religiosity plummets it becomes more suspect.) } \\
\text { "To me, God and country are tied," explained a } \\
\text { woman who broke into the House speaker's office. } \\
\text { "To me they're one and the same."” (TheWeek) }\end{array}$ & & \\
\hline Anti-Semitism & $\begin{array}{l}\text { "Two white nationalists known for racist and } \\
\text { anti-Semitic rhetoric livestreamed to their online } \\
\text { followers after breaking into the Capitol during } \\
\text { the deadly insurrection. AP. }\end{array}$ & $\begin{array}{l}\text { "Many ethnic, racial and religious groups were } \\
\text { targeted by rioters donning paraphernalia with } \\
\text { historically inflammatory slogans, symbols and } \\
\text { tropes. While the hate was widespread, Jewish } \\
\text { Americans were subject to specific discrimination } \\
\text { evidenced by Nazi Holocaust imagery and } \\
\text { rhetoric." (Moment). }\end{array}$ & \\
\hline Parler users & $\begin{array}{l}\text { "At least several users of the far-right social } \\
\text { network Parler appear to be among the horde of } \\
\text { rioters that managed to penetrate deep inside the } \\
\text { U.S. Capitol building and into areas normally } \\
\text { restricted to the public, according to GPS } \\
\text { metadata linked to videos posted to the platform } \\
\text { the day of the insurrection in Washington." } \\
\text { (Gizmodo) }\end{array}$ & $\begin{array}{l}\text { "On social media sites used by the far-right, such } \\
\text { as Gab and Parler, directions on which streets to } \\
\text { take to avoid the police and which tools to bring } \\
\text { to help pry open doors were exchanged in } \\
\text { comments. At least a dozen people posted about } \\
\text { carrying guns into the halls of Congress." } \\
\text { (NYTimes.) }\end{array}$ & \\
\hline
\end{tabular}


Table SI-10: Journalistic and slanted coverage of 'March to Save America' protest and riot participants, January 6, 2021

\begin{tabular}{|c|c|c|c|}
\hline Characteristic & $\begin{array}{c}\text { Source } 1 \\
\end{array}$ & Source 2 & Source 3 \\
\hline Economics & $\begin{array}{l}\text { "Based on the early arrests and news reports } \\
\text { from the riot, the Capitol insurrectionists } \\
\text { represent a bigger slice of white America than } \\
\text { just the low-class knuckle-draggers who rolled in } \\
\text { from the sticks on Donald Trump's command. } \\
\text { Many of the protesters and rioters we have met } \\
\text { through rap sheets and press accounts are solidly } \\
\text { middle class. Some of them are professionals and } \\
\text { business people who are as cosmopolitan as } \\
\text { Flanagan, a longtime Atlantic writer who } \\
\text { ordinarily cuts through sanctimony and sloppy } \\
\text { thinking." (Politico) }\end{array}$ & & \\
\hline Proud boys & $\begin{array}{l}\text { "Federal prosecutors charged a leader of the } \\
\text { far-right group the Proud Boys for his role in the } \\
\text { Capitol riot that left five people dead in the } \\
\text { nation's capital earlier this month." (NYPost). } \\
\text { "Mr Biggs was described as being an organiser } \\
\text { for the Proud Boys by the FBI, and was charged } \\
\text { with disorderly conduct, obstructing an official, } \\
\text { and entering a restricted area at the US Capitol } \\
\text { on the day of the attack." (Independent) }\end{array}$ & $\begin{array}{l}\text { "Spazzo didn't stop at just smashing the window } \\
\text { and leading the insurrectionists inside the } \\
\text { Capitol. In one of the most dramatic photos of } \\
\text { the failed siege, the man can be seen deep inside } \\
\text { the building confronting Capitol Police officers, } \\
\text { still brandishing his riot shield. Beside him is the } \\
\text { young man in tactical gear who'd marched } \\
\text { alongside Proud Boy leaders earlier in the day." } \\
\text { (Vice). }\end{array}$ & \\
\hline
\end{tabular}


Slanted media coverage

\begin{tabular}{|c|c|c|c|}
\hline Characteristic & Source 1 & Source 2 & Source 3 \\
\hline Leftist activist & $\begin{array}{l}\text { "A Utah-based left-wing activist is facing } \\
\text { criminal charges for allegedly participating in the } \\
\text { Capitol Hill riot last week." (Breitbart) }\end{array}$ & $\begin{array}{l}\text { "Meanwhile, left-wing activist John Sullivan, who } \\
\text { was arrested and charged in connection to the } \\
\text { Capitol Hill riot, remained on the social media } \\
\text { platform for another two weeks after the } \\
\text { president was banned." (Breitbart) }\end{array}$ & $\begin{array}{l}\text { "A left-wing activist who told Fox News last week } \\
\text { that he'd followed a pro-Trump mob into the } \\
\text { Capitol in order to "document" the siege is now } \\
\text { the subject of a criminal complaint in connection } \\
\text { with his alleged participation, according to the } \\
\text { U.S. Justice Department." (FOX) }\end{array}$ \\
\hline Antifa & $\begin{array}{l}\text { "Washington Times posted an article claiming } \\
\text { that antifa members were also among the people } \\
\text { that breached the Capitol. They later edited the } \\
\text { post and apologized for the error admitting that } \\
\text { there were no antifa members storming the } \\
\text { Capitol. Here is an article on Washington Post } \\
\text { (WashPo,, where they say "Citing a widely } \\
\text { contested article published by the Washington } \\
\text { Times, Gaetz admitted he does not know "if the } \\
\text { reports are true." But, he said to audible boos, } \\
\text { "some of the people who breached the Capitol } \\
\text { today were not Trump supporters. They were } \\
\text { masquerading as Trump supporters and in fact, } \\
\text { were members of the violent terrorist group } \\
\text { antifa."." Here is a link to an edited article - } \\
\text { (WashTimes. }\end{array}$ & $\begin{array}{l}\text { "Former governor of Alaska Sarah Palin has } \\
\text { claimed without evidence that Capitol rioters } \\
\text { may have been Antifa dressed as far-right Trump } \\
\text { supporters." (Independent) }\end{array}$ & $\begin{array}{l}\text { Several Republicans have claimed that antifa was } \\
\text { involved in the riots. Their claims were } \\
\text { debunked. Among them is Ken Paxton } \\
\text { (Republican State senator) who tweeted "those } \\
\text { who stormed the capitol yesterday were not } \\
\text { Trump supporters. They have been confirmed to } \\
\text { be Antifa." (PolitiFact). }\end{array}$ \\
\hline
\end{tabular}




\section{Appendix References}

Bivand, Roger S, Edzer J Pebesma, Virgilio Gomez-Rubio and Edzer Jan Pebesma. 2013. Applied spatial data analysis with $R$. Vol. 2 Springer.

Bivand, Roger, Tim Keitt and Barry Rowlingson. 2019. rgdal: Bindings for the 'Geospatial' Data Abstraction Library. R package version 1.4-8.

URL: https://CRAN.R-project.org/package=rgdal

code by Richard A. Becker, Original S, Allan R. Wilks. R version by Ray Brownrigg. Enhancements by Thomas P Minka and Alex Deckmyn. 2018. maps: Draw Geographical Maps. R package version 3.3.0.

URL: https://CRAN.R-project.org/package=maps

Colella, Fabrizio, Rafael Lalive, Seyhun Orcan Sakalli and Mathias Thoenig. 2019. "Inference with Arbitrary Clustering." IZA Discussion Paper No. 12584.

Correia, Sergio. 2016. Linear Models with High-Dimensional Fixed Effects: An Efficient and Feasible Estimator. Technical report. Working Paper.

Dowle, Matt and Arun Srinivasan. 2020. data.table: Extension of 'data.frame'. R package version 1.13.6.

URL: https://CRAN.R-project.org/package=data.table

Grolemund, Garrett and Hadley Wickham. 2011. "Dates and Times Made Easy with lubridate." Journal of Statistical Software 40(3):1-25.

URL: https://www.jstatsoft.org/v40/i03/

Hijmans, Robert J. 2019. geosphere: Spherical Trigonometry. R package version 1.5-10.

URL: https://CRAN.R-project.org/package=geosphere

Kahle, David and Hadley Wickham. 2013. "ggmap: Spatial Visualization with ggplot2." The $R$ Journal 5(1):144-161.

URL: https://journal.r-project.org/archive/2013-1/kahle-wickham.pdf

Pebesma, Edzer. 2018. "Simple Features for R: Standardized Support for Spatial Vector Data." The R Journal 10(1):439-446.

URL: https://doi.org/10.32614/RJ-2018-009

R Core Team. 2020. R: A Language and Environment for Statistical Computing. Vienna, Austria: R Foundation for Statistical Computing.

URL: https://www.R-project.org/

Wickham, Hadley. 2016. ggplot2: Elegant Graphics for Data Analysis. Springer-Verlag New York.

URL: https://ggplot2.tidyverse.org 
Wickham, Hadley and Jennifer Bryan. 2019. readxl: Read Excel Files. R package version 1.3.1.

URL: https://CRAN.R-project.org/package=readxl

Wickham, Hadley, Mara Averick, Jennifer Bryan, Winston Chang, Lucy D’Agostino McGowan, Romain François, Garrett Grolemund, Alex Hayes, Lionel Henry, Jim Hester, Max Kuhn, Thomas Lin Pedersen, Evan Miller, Stephan Milton Bache, Kirill Müller, Jeroen Ooms, David Robinson, Dana Paige Seidel, Vitalie Spinu, Kohske Takahashi, Davis Vaughan, Claus Wilke, Kara Woo and Hiroaki Yutani. 2019. "Welcome to the tidyverse." Journal of Open Source Software 4(43):1686.

Wickham, Hadley, Romain François, Lionel Henry and Kirill Müller. 2020. dplyr: A Grammar of Data Manipulation. R package version 1.0.2.

URL: https://CRAN.R-project.org $/$ package $=d$ plyr 